\title{
CIENCIA Y OCUPACIÓN DEL TERRITORIO EN LAS ISLAS SHETLAND DEL SUR (ANTARTIDA MARÍTIMA): IMPLICACIONES TERRITORIALES Y AMBIENTALES DE LAS BASES CIENTÍFICAS
}

\author{
Enrique SERRANO CAÑADAS \\ Departamento de Geografia. Universidad de Valladolid
}

\section{INTRODUCCIÓN.}

El archipiélago de las islas Shetland del Sur está formado por once islas mayores alineadas entre el Paso de Drake y el mar de Bansfield, en el océano Antártico, inmediatamente al norte de la Península Antártica. Tienen una extensión de $4.700 \mathrm{~km}^{2}$ y se localizan entre los $61^{\circ} 59^{\prime}$ y $63^{\circ} 20^{\prime}$ de latitud Sur, y los $57^{\circ} 40^{\prime}$ y los $62^{\circ} 45^{\prime}$ de latitud. Tan sólo el $10 \%$ de la superficie del archipiélago está libre de hielo, y es en estos ámbitos, compartimentados en cabos, puntas y estrechas franjas costeras, donde se localizan las ocupaciones humanas de las Islas Shetland del Sur. Presentan topografías escalonadas en replanos que se alzan paulatinamente hasta los 270 metros en Rey Jorge. En zonas con relieves montañosos, presentan topografías más enérgicas, con pocos espacios horizontales. Este inmenso mundo blanco presenta un paisaje de belleza extrema y es, a la vez, duro y hostil a la vida, por lo que ésta es muy limitada. En estos espacios se concentra durante el verano austral la fauna marina, con grandes colonias de pigüinos, elefantes marinos, lobos marinos, petreles, etc. Es en las márgenes del continente donde se han instalado la mayor parte de las bases presentes actualmente en la Antártida, pues la ausencia de glaciares facilita los accesos y el desarrollo de la vida cotidiana.

\section{ESTABLECIMIENTO DE LA RED DE BASES CIENTÍFICAS.}

\subsection{Los inicios: políticos, militares, aventureros y científicos.}

Las exploraciones geográficas antárticas siempre estuvieron acompañadas de estudios científicos que permitieron conocer la naturaleza de las zonas exploradas y se enmarcan en la tradición de los grandes viajes científicos, aunque en su última parte se impone el objetivo prioritario de alcanzar el polo (KIRWAN, 1965; VICTOR, 1965; HEADLAND, 1985). Pero junto al afán explorador y científico, no debemos olvidar que la aventura antártica no ha partido de la exploración y conocimiento geográfico y científico, sino de los intereses políticos y económicos en la ocupación de su espacio, en la realización de expediciones geográficas y en la financiación de proyectos científicos. 
Gran Bretaña reclama en 1908 este territorio y crea los Falkland Territories. En 1917 ajustará los límites territoriales de la reclamación, pues en el acta anterior, por error, habia incluido parte del cono sur americano. La administración territorial británica conlleva la concesión de licencias para la caza de la ballena y los recelos inmediatos de países como Argentina y Chile, con intereses territoriales y económicos en la zona.

La Sociedad Ballenera de Magallanes, chilena, instala una factoría ballenera en Puerto Foster, Decepción, en 1906, aunque los balleneros estuvieron utilizando la isla Decepción desde al menos 1888. Funcionará a pleno rendimiento hasta que la adquiere la compañía noruega Hvalfangerselskabet Hector A/S (Hector whaling Company, Tongsberg) que monta una industria para la obtención de aceite de ballena. La factoría ballenera de Decepción es el primer asentamiento humano de las Shetland del Sur, en el que residirán, según ARAMAGO (1949), hasta 5.000 trabajadores. En 1931se cierra la factoría y las erupciones volcánicas de 1968 y 1970 destruyen hornos, dependencias, maquinaria y depósitos, hoy parcialmente enterrados y dispersos por las playas de Puerto Foster. En 1995 todo el conjunto fué declarado Sitio Histórico y monumento $\mathrm{n}^{\mathrm{0}} 71$, de modo que hoy es reconocido como el principal resto histórico del archipiélago, testigo de una actividad industrial capaz de transformar parcialmente el paisaje de la ensenada, y una de las principales atracciones turísticas del archipiélago, y uno de los puntos mas visitados de la Antártida (SERRANO, 2001).

En 1923 Gran Bretaña crea el British Discovery Comitte, dependiente de la Oficina Colonial, organismo que se encarga del estudio y reconocimiento del territorio de las Falkland Dependencies. Para ello, promueve, entre 1935 y 1949, trece viajes de estudio y reconocimiento de la zona que significan el inicio de las investigaciones sistemáticas, centradas en la oceanografia, la biología y las explotaciones balleneras, esta última actividad la principal fuente de financiación del territorio. Se están poniendo las bases para que la gestión e intervención de un estado sobre el territorio permita su completa anexión. Sin embargo, Argentina reaccionará con reclamaciones oficiales en 1925 y 1937, y con la creación de una Comisión que define el territorio antártico argentino, germen del futuro Instituto Antártico Argentino. En el mismo año, y siguiendo las mismas directrices, Chile reclamará una porción del territorio antártico, también en el sector de la península Antártica, de tal modo que desde este momento se produce la superposición de reclamaciones territoriales de tres naciones sobre el mismo espacio.

Las tres naciones orientarán sus actuaciones en la política de anexión de esta porción antártica. Si Gran Bretaña se basa en la ocupacón y gestión efectiva del territorio, con servicios estatales (correo, impuestos, control de pesquerías, etc), los países americanos se apoyarán en la herencia histórica, partiendo de la herencia de los territorios del Imperio español por Chile y Argentina tras su independencia, y por tanto fueron los pimeros en navegar y ocupar las aguas de la Antártida marítima. Pero pronto el camino es el de la ocupación efectiva del territorio, lanzándose en una lenta carrera que evolucionará hacia la proliferación de asentamientos en las islas Shetland del Sur.

En 1943, en plena guerra y como acción militar, los británicos inician la "operación Tabarín", que supondrá la instalación de tres bases (A, B y G), montadas en 1944, que pasan a ser estaciones meteorológicas para el apoyo a la navega- 
ción. Es el primer paso en la instalación de bases ${ }^{1}$ que con objetivos técnicos y militares, pasaran a quehaceres científicos y civiles con la llegada de la paz. La base "B" se instalará en la caleta Balleneros, junto a la factoría ballenera de la isla Decepción, con el objetivo de controlar la presencia de submarinos alemanes en Puerto Foster, y la Base "C" se instalará en la península Keller, en el interior de la bahía Almirantazgo, en la isla Rey Jorge. Su utilización fue continua hasta la erupción volcánica de 1965, cuando fue abandonada por el riesgo volcánico. La base "G" fue transportada en 1996 por el gobierno brasileño al museo del Scott Polar Research Institut en Cambridge.

En la posguerra y en un clima de tensión diplomática que se reflejará también en las relaciones entre las bases y dotaciones de las islas Shetland del Sur, con pequeñas crisis militares hasta los años 50 , los estados americanos pasan a la acción. En 1947 Chile instala en la isla Greenwich su primera base antártica, la Base "Soberanía", hoy Arturo Prat. Es un ambicioso proyecto de ocupación efectiva y control que incluirá la construcción un año más tarde de la base O'Higgins (1948), ya en el continente (península Antártica) y en 1951 su tercera base, la González Videla, al Sur del estrecho de Gerlache, en la península Antártica. Argentina instala en 1948 el destacamento naval de la isla Decepción, magnífica base bien dotada y equipada con medios logísticos. Esta ocupación mediante bases militares implica también las labores de registro de datos técnicos y científicos en programas de meteorología, ionización, atmósfera, volcanismo, geología, oceanografía, que permiten iniciar la investigación científica sistemática en los años 50 . Pero su razón será política y geoestratégica, y estos objetivos marcarán la elección de sus emplazamientos.

En los años cincuenta las políticas de británicos, chilenos y argentinos serán divergentes. Si los británicos optan por el control efectivo y desarrollo de las bases, con especial importancia para la isla Decepción, donde se completa la base con un aeródromo, Chile se inclinará por una política de construcción de refugios, de modo que con bajo coste puede tener presencia en multitud de puntos. En 1952 construyen Yankee Bay en la Isla Greenwich y en 1956 el refugio Coopermine en la Isla Roberts. Argentina, que centra sus actividades en mayor medida hacia la península Antártica, finaliza sus bases en este ámbito, San Martín en el 51, Esperanza en el 52, y se centra en 1953 en las Shetland del Sur, construyendo los Destacamentos Navales de Jubany, en la isla Rey Jorge, de apoyo aeronaval para máquinas anfibias, Cámara, en Media Luna, y finalmente el refugio naval Gurruchaga, en isla Nelson. Para el año 1957 está establecida la red de bases y refugios de los estados con intereses en la zona. Tres bases Argentinas, dos británicas y dos chilenas, junto a tres refugios, formarán una malla de asentamientos bien estacionales, bien anuales. A esta red hay que añadir la construcción en 1963 de la Base antártica Gutiérrez, de Chile, en la Isla Decepción, que implica la presencia de los tres estados reclamantes en Puerto Foster. Las tres serán abandonadas y esta última totalmente destruida por las erupciones de 1965, 67 y 70.

\footnotetext{
${ }^{1}$ Anteriormente se habían instalado campamentos en los territorios subantárticos y en el continente desde los que se realizaron las exploraciones del interior y la costa. Sin embargo, las bases son emplazamientos fijos cuyo fin es la recolección de datos e información. La instalada en 1904 por Argentina en las Orcadas del Sur, tras la cesión británica de los cuarteles de invierno de la expedición escocesa de Bruce (1902-04), es la primera base científica de las islas subantárticas.
} 
La proclamación del Año Geofísico Internacional en 1957/58 significa el primer esfuerzo internacional serio por afrontar el conocimiento científico del continente, una vez conocida sus extensión tras los vuelos aéreos de los años 40. Será, pues, el primer paso para un cambio radical en la ocupación efectiva de la Antártida.

\subsection{El Sistema del Tratado Antártico y su influencia territorial.}

En 1957 el Consejo internacional de Uniones Científicas (ICSU) declara a la Antártida objetivo para la investigación y se inicia un proceso que culminará con la creación del Comité Cientifico para la Investigación antártica (SCAR) y con la firma del Tratado Antártico, el 1 de Diciembre de 1959. En él se establecen catorce artículos entre los que destaca la congelación de las reclamaciones territoriales, el uso pacífico del continente, la conservación de la naturaleza y su dedicación a la investigación científica, abierta a la cooperación internacional. El año geofísico Internacional señala una nueva época en la investigación antártica y los avances serán muchos. Durante la guerra fría, soviéticos y norteamericanos se resevaron la posibilidad de reclamaciones territoriales sobre toda la Antártida pero no reclamaron ningún espacio. De este modo se pudo elaborar el Tratado Antárti$\mathrm{co}^{2}$, que a través del Comité Científico de Investigaciones Antárticas (SCAR) que regula la participación en la gestión antártica, de modo que la investigación científica es obligatoria para formar parte consultiva del Tratado, junto a la postergación de las reclamaciones territoriales. Se inicia así una colaboración internacional que ha permitido avances considerables en el entendimiento común de este continente sin dueños (MARTíNEZ DE PISÓN, 1991).

Durante el periodo del AGI se construyen más de 40 estaciones de investigación en la Antártida, centrándose en el continente ${ }^{3}$. Este esfuerzo, y la configuración previa de la red de estaciones conlleva para las Shetland del Sur un periodo de continuidad territorial, pero significativo por el abandono de las tensiones entre los estados con bases, que postergan sus reclamaciones territoriales. Gran Bretaña, desde la entrada en vigor del Tratado Antártico divide en dos las Falkland Dependencies, de modo que se crea el Territorio Antártico Británico, centralizando la gestión de investigación en el British Antarctic Survey (BAS), órgano de investigación y asesoría dependiente del Foreing Office (Asuntos Exteriores).

Habrá que esperar a 1968 para que nuevos países se interesen por las Shetland del Sur como destino de sus bases antárticas. El primero será la Unión Soviética, potencia antártica que busca tener una red de bases en la Antártida y encuentra en las islas Shetland del Sur el lugar idóneo para una base de investigación y apoyo logístico a los buques oceanográficos de su flota antártica. Se instala

\footnotetext{
${ }^{2}$ Sería firmado por doce paises en diciembre de 1959 y entraría en vigor en junio de 1961. En la actualidad son 39 los paises firmantes, 26 con derecho a voto. España se adhirió al Tratado Antártico como observador en 1982, pasando a miembro consultivo, ya con derecho a voto, en 1988. En 1990 forma parte del SCAR, con lo que culmina su integración en los organismos antárticos internacionales.

${ }^{3}$ En este momento se forma la red de bases soviética y se completa la de los norteameric anos. Los esfuerzos se dirigen a la instalación de la Amundsen-Scott, en el polo sur geográfico, la Mirny en el polo Sur magnético, o la Vostok en el de inaccesibilidad.
} 
en un lugar emblemático, la Península Fildes, en la isla Rey Jorge. Al año siguiente, en 1969, y en el mismo lugar, se construye la base antártica chilena Marsh, también destinada a centro de operaciones navales y como punto intermedio entre el cono Sur y la península antártica, donde se localiza la base más importante, O'Higgins. La base Marsh tiene funciones logísticas prioritariamente, y de investigación en segundo lugar, construyéndose en 1980 una pista de aterrizaje que significará un profundo cambio territorial. Polonia, nación experta en la investigación polar, trata de incluirse entre las naciones consultivas del Tratado Antártico y en 1977 instala la base Artowski en la bahía Almirantazgo, consiguiendo ser estado consultivo ese mismo año.

A partir de los años ochenta se produce un cambio en la orientación de las Shetland del Sur, siguiendo el modelo polaco, pero con países con escasa tradición y experiencia antártica. Los estados sudamericanos, con Brasil a la cabeza, desarrollan en los años 80 la teoría de la "defrontaçao", que siguiendo la teoría de los sectores polares en su concepción más extrema, tiene como fin debilitar, en un marco común, los presupuestos británicos. Esta teoría defiende que el reparto territorial de la Antártida debe realizarse entre los países americanos con costa, en función de las longitudes de costa expuesta al Atlántico y Pacífico. Esta teoría ha llevado a paises como Ecuador, Uruguay, Perú y Brasil, junto a Chile y Argentina, a tener opciones en el antártico. Las diplomacias nacionales no tratan tanto de conseguir porciones de terreno como disponer de peso en los foros internacionales, más si se unen en la aceptación de una teoría. Pero el tratado antártico obliga a demostrar la realización de investigacón antártica para ser miembro consultivo y esto, es práctica común, se consigue mediante la instalación de una base antártica. La lógica diplomática conduce a la necesidad de instalar una base y que esta se localice en la porción de tierra sobre la que pueda pesar algún día una reclamación. Todo ello desembocó en la proliferaración de bases en las Shetland del Sur entre 1984 y 1985. Las facilidades encontradas en la presencia de la pista de aterrizaje chilena y los convenios de colaboración entre estados e institutos antárticos convino para que los nuevos asentamientos se ubicaran en las proximidades de la base Marsh, en la Isla Rey Jorge. Primero será Brasil, quien en 1984 se instala en la Península Keller, junto a la abandonada Base "G" británica, en la bahía Almirantazgo. Al año siguiente, no sin controversias, se monta la base uruguaya Artigas, en el extremo más septentrional de la Península Fildes, construyéndose una pista de $4 \mathrm{kms}$. que enlaza Fildes con Bellinghausen y Marsh.

Ese mismo año la República Popular China desembarca también en la isla Rey Jorge para construir la base Gran Muralla en su primera expedición antártica, consiguiendo en el mismo año la categoría de miembro consultivo. Esta se ubica en el extremo sur de la penínsla Fildes, y se enlaza también con una pista a Bellinghausen y Marsh.

Posteriormente, y en función de las mismas premisas: teoría de la defrontaçao, facilidades logísticas chilenas y la colaboración entre estados sudamericanos, se han instalado otras bases en Bahía Almirantazgo, la base de Ecuador, en Punta Henneqin, en 1988, y la base Machu Pichu, peruana, en la bahía Mckellar, en 1989. También en las cercanías de la Península Fildes, pero en la Isla Nelson, se ubicará la base-refugio Checa "Václav Vojtech", habitada en 1997. En este periodo se construyen refugios de investigación en la isla Nelson (Croubl, brasileño, 
Chino en Standbury Point, Gurruchaga, de Argentina, en Harmony Point), Fildes (Rambo, brasileño), Elefante (Brasil), Ardley (Chile, Alemania y Argentina), Bahía Almirantazgo (Copacabana, USA) y cabo Shirref, en Livingston (Chile).

Tres nuevos países se incorporarán a partir de 1988 al poblamiento de las Shetland del Sur, Corea del Sur, España y Bulgaria. Los coreanos instalan su base en 1988, en la isla Rey Jorge, próxima a Fildes, pero en un lugar solitario, en la península Barton. Bulgaria decide continuar sus investigacones antárticas, precedidas de la construcción de un refugio en isla Livingston, a partir de 1997. Con apoyo del programa español y buques comerciales, instalan la base StKliment en Punta Hespérides (is la Livingston), ocupada durante el verano.

CUADRO 1. Bases cientificas de las Islas Shetland del Sur.

\begin{tabular}{llll}
\hline \multicolumn{1}{c}{ Base } & \multicolumn{1}{c}{ País } & \multicolumn{1}{c}{ Año } & \multicolumn{1}{c}{ Coordenadas } \\
\hline Prat & Chile & 1947 & $62^{\circ} 30^{\prime} \mathrm{S} / 59^{\circ} 41^{\prime} \mathrm{O}$ \\
Decepción & Argentina & 1948 & $62^{\circ} 55^{\prime} \mathrm{S} / 60^{\circ} 46^{\prime} \mathrm{O}$ \\
Jubany & Argentina & 1953 & $62^{\circ} 144^{\prime} \mathrm{S} / 58^{\circ} 38^{\prime} \mathrm{O}$ \\
Cámara & Argentina & 1953 & $62^{\circ} 36^{\prime} \mathrm{S} / 59^{\circ} 54^{\prime} \mathrm{O}$ \\
\hline Coopermine & Chile & 1956 & $62^{\circ} 23^{\prime} \mathrm{S} / 59^{\circ} 40^{\prime} \mathrm{O}$ \\
Bellinghausen & Rusia & 1968 & $62^{\circ} 12^{\prime} \mathrm{S} / 58^{\circ} 56^{\prime} \mathrm{O}$ \\
Frei-Marsh & Chile & 1969 & $62^{\circ} 13^{\prime} \mathrm{S} / 58^{\circ} 56^{\prime} \mathrm{O}$ \\
Artowski & Polonia & 1977 & $62^{\circ} 09^{\prime} \mathrm{S} / 58^{\circ} 29^{\prime} \mathrm{O}$ \\
\hline Ferráz & Brasil & 1984 & $62^{\circ} 05^{\prime} \mathrm{S} / 58^{\circ} 20^{\prime} \mathrm{O}$ \\
Gran Muralla & Rep. Pop. China & 1985 & $62^{\circ} 13^{\circ} \mathrm{S} / 58^{\circ} 56^{\prime} \mathrm{O}$ \\
Artigas & Uruguay & 1985 & $62^{\circ} 11^{\prime} \mathrm{S} / 58^{\circ} 51^{\prime} \mathrm{O}$ \\
Maldonado & Ecuador & 1985 & $62^{\circ} 27^{\prime} \mathrm{S} / 59^{\circ} 44^{\prime} \mathrm{O}$ \\
\hline King Sejong & Corea del Sur & 1988 & $62^{\circ} 133^{\prime} \mathrm{S} / 58^{\circ} 47^{\prime} \mathrm{O}$ \\
Juan Carlos I & España & 1989 & $62^{\circ} 40^{\prime} \mathrm{S} / 60^{\circ} 20^{\prime} \mathrm{O}$ \\
Machu Pichu & Perú & 1989 & $62^{\circ} 05^{\prime} \mathrm{S} / 58^{\circ} 28^{\prime} \mathrm{O}$ \\
Gabriel de Castilla & España & 1993 & $62^{\circ} 58^{\prime} \mathrm{S} / 60^{\circ} 40^{\prime} \mathrm{O}$ \\
ST. Kliment & Bulgaria & 1997 & $62^{\circ} 38^{\prime} \mathrm{S} / 60^{\circ} 22^{\prime} \mathrm{O}$ \\
\hline
\end{tabular}

España sera el último país en acceder a la región para instalar sendas bases Juan Carlos I y Gabriel de Castilla. La primera nace de la necesidad de realizar investigaciones científicas para ser miembro consultivo, para lo cual el $\mathrm{M}^{\mathrm{o}}$ de Asuntos Exteriores contactará con el grupo de científicos capaz de llevarlo a cabo por su experiencia previa en tierra antártica ${ }^{4}$. En este caso, la experiencia personal y los contactos con las instituciones científicas polacas, así como con su asesoramiento y apoyo, hicieron posible encontrar un emplazamiento idóneo en las Shetland del Sur, la Isla Livingston, desprovista de bases científicas hasta ese momento. En la campaña 1987/88 se instala la B.A.E Juan Carlos I, accediendo a la categoría de miembro consultivo en octubre de $1988^{5}$. Con posterioridad, y debi-

\footnotetext{
${ }^{4}$ A este respecto son interesantes las lecturas de Calvo (1992), CASTEllví (1996), Nogueira (1997) y LóPEZ (2000).

${ }^{5}$ El esfuerzo científico para el acceso a la categoría consultiva fue acompañado de varias iniciativas, algunas extraoficiales, como el viaje de la Goleta Idus de marzo en 1982/83, y las restantes oficiales, como la campaña Antártica del Instituto de Ciencias del Mar (CSIC), la Misión cientificopesquera a la Antártida del IEO, en 1986/87, la expedición de la Armada en el buque Río Baker, y el
} 
do a la dinámica interna de la presencia española en la Antártida se montará un refugio en la Isla Decepción, en 1993, cuando por entonces no está en activo ninguna base en la isla, pero sí científicos españoles y argentinos que mantienen un programa de control volcanológico. Este refugio pasará a constituirse como BAE Gabriel de Castilla a partir del año $1998^{6}$.

Se completa, así, la red de asentamientos que conforman un total de nueve bases permanentes, siete bases estivales y, al menos diez refugios, así como tres emplazamientos abandonados de modo definitivo. Los contactos y las colaboraciones científicas determinan el crecimiento de bases cercanas entre sí y la colonización paulatina con un centro, Fildes en Rey Jorge, y zonas marginales. Podemos establecer una doble cadena que ha permitido la agrupación de bases en el archipélago, por un lado los estados sudamericanos, cuyo apoyo en la logística chilena ha permitido la instalación y primeros pasos de cuatro bases; y por otro lado, una más compleja, basada en las relaciones institucionales y científicas que sería la iniciada por Bellinhausen, y continuada con Artowski, Juan Carlos I, Gabriel de Castilla y St.Kliment. Finalmente, China y Corea del Sur, así como el refugio americano de Copacabana, se establecerán de modo independiente, pero buscando las facilidades del archipélago y de la Isla Rey Jorge en particular.

\section{LAS BASES CIENTÍFICAS EN LA ACTUALIDAD.}

En la Antártida se observa una distribución de las bases muy desigual. El 53\% de las bases se localizan en la antártida marítima, entre los 20 y $98^{\circ}$ oeste. De esta porción de territorio, donde se localizan 36 bases, el $45 \%$ se localiza en las Shetland del Sur, una ínfima parte del territorio abarcado. En el resto de la Antártida se localiza el $32 \%$ de las bases en la porción oriental, entre $160^{\circ} \mathrm{E}$ y los $20^{\circ}$ $\mathrm{W}$, mientras un $15 \%$ se ubica en la zona de Ross, entre $\operatorname{los} 90^{\circ}$ y los $160^{\circ} \mathrm{E}$ (MCKENZIE, 1988; POUPIN Y BURGOS, 1994). En este caso, el proceso de poblamiento es singular para la Antártida, pues se ha ido ocupando y abandonando en función de los usos históricos de los recursos, primero cazadores de focas, en asentamientos provisionales, posteriormente los balleneros, con importantes asentamientos, en tercer lugar los militares y finalmente la actividad científica. Las bases existentes en la actualidad en las Shetland del Sur proceden como hemos visto de un origen militar en la mitad de los casos y científico en el resto. Es esta una particularidad propia del archipiélago, posible por su ya larga historia de poblamiento.

Los fundamentos del poblamiento en las Shetland del Sur son la presencia de un medio hostil, el aislamiento de la civilización, que implica la imposiblididad de suministrarse en el terreno y obliga al transporte de todos los útiles necesarios para la vida, y la historia del poblamiento, que determina herencias del pasado e influencias, con una tendencia aglomerativa muy dinámica que han señalado

programa Vulcantur (CsIC) en 1987/88. La B.A.E. Juan Carlos I significará el paso obligado, aunque no escrito, para acceder al rango de miembro consultivo y ha sido un modelo ejemplar en la actividad antártica.

${ }^{6}$ La B.A.E. Gabriel de Castilla, con un largo itinerario (en el marco del joven programa nacional) en la investigación antártica desde su configuración como campamento, primero, y refugio, después, está dirigida por personal del Ejército de Tierra. 
CUADRO 2. Tipología de asentamientos antárticos.

\begin{tabular}{|c|c|c|c|c|c|c|c|c|}
\hline \multirow[b]{2}{*}{ Base } & \multirow[b]{2}{*}{$\begin{array}{l}\text { Año } \\
(1)\end{array}$} & \multicolumn{2}{|r|}{ Edific. } & \multirow[b]{2}{*}{$\begin{array}{l}\text { Din. } \\
\text { (4) }\end{array}$} & \multicolumn{2}{|c|}{ Objeto } & \multirow[b]{2}{*}{ Uso } & \multirow[b]{2}{*}{$\begin{array}{c}\text { Entorno } \\
\text { (6) }\end{array}$} \\
\hline & & $\begin{array}{l}\mathbf{N}^{0} \\
(2)\end{array}$ & $\begin{array}{c}\text { Tipo } \\
\text { (3) }\end{array}$ & & $\begin{array}{l}\text { Ciencia } \\
\text { (5) }\end{array}$ & Servicios & & \\
\hline Prat $(\mathrm{Ch})$ & 1947 & & & & & & An. & Paisaje glaciar. \\
\hline $\begin{array}{l}\text { Decepción } \\
\text { (Arg) }\end{array}$ & 1948 & $\begin{array}{l}7 \\
3\end{array}$ & $\begin{array}{c}\text { A } \\
4\end{array}$ & De. & GE, SI, VO & $\begin{array}{l}\text { Helipuerto, } \\
\text { Embarcad. }\end{array}$ & Estac. & $\begin{array}{l}\text { Geológico. Volca- } \\
\text { nismo, lacustre. }\end{array}$ \\
\hline $\begin{array}{l}\text { Jubany } \\
\text { (Arg) }\end{array}$ & $\begin{array}{l}1953 / \\
1982\end{array}$ & $\begin{array}{c}10 \\
5\end{array}$ & $\begin{array}{c}\text { A } \\
2 / 3\end{array}$ & Ex. & $\begin{array}{l}\mathrm{BI}, \mathrm{HI}, \mathrm{ME}, \\
\mathrm{CO}_{2}\end{array}$ & $\begin{array}{l}\text { Helipuer- } \\
\text { to,Vehículos } \\
\text { apoyo. }\end{array}$ & An. & Fauna. \\
\hline $\begin{array}{l}\text { Cámara } \\
\text { (Arg) }\end{array}$ & 1953 & $\begin{array}{l}4 \\
1\end{array}$ & $\begin{array}{c}\mathrm{A} \\
1 \\
\end{array}$ & Eq. & ME, GL, OC & & Estiv. & $\begin{array}{l}\text { Geomorfología, } \\
\text { fauna. }\end{array}$ \\
\hline $\begin{array}{l}\text { Coopermine } \\
\text { (Ch) }\end{array}$ & $\begin{array}{l}1956 / \\
1977\end{array}$ & $\begin{array}{l}5 \\
2\end{array}$ & $\begin{array}{c}\mathrm{B} / \mathrm{A} \\
1\end{array}$ & Eq. & BI, GE & --- & Esp. & $\begin{array}{l}\text { Fauna,vegetación, } \\
\text { relieve. }\end{array}$ \\
\hline $\begin{array}{l}\text { Bellinghausen } \\
\text { (R) }\end{array}$ & 1968 & 17 & $\begin{array}{c}\mathrm{B} / \mathrm{C} \\
3 \\
\end{array}$ & De. & BI, ME, IC & $\begin{array}{l}\text { Vehícu- } \\
\text { los,Tienda }\end{array}$ & An. & ---- \\
\hline $\begin{array}{l}\text { Frei-Marsh } \\
\text { (Ch) }\end{array}$ & 1969 & $\begin{array}{c}22 \\
1\end{array}$ & $\begin{array}{c}\mathrm{A} / \mathrm{B} / \mathrm{C} / \mathrm{D} \\
3-4\end{array}$ & Ex. & $\mathrm{ME}$ & $\begin{array}{l}\text { Aerop., Co- } \\
\text { rreo, Hotel, } \\
\text { Banco, Hosp., } \\
\text { Tienda, Igle., } \\
\text { Tel. púb. }\end{array}$ & An. & ---- \\
\hline $\begin{array}{l}\text { Artowski } \\
\text { (Pol) }\end{array}$ & 1977 & $\begin{array}{l}3 \\
2 \\
\end{array}$ & $\begin{array}{c}\mathrm{B} \\
2(1) \\
\end{array}$ & Eq.o & BI, GE, ME. & Helipuerto & An. & Vegetación \\
\hline $\begin{array}{l}\text { Feraz } \\
(\mathrm{Br})\end{array}$ & 1984 & $\begin{array}{l}5 \\
4 \\
\end{array}$ & $\begin{array}{c}\mathrm{B} \\
1 \\
\end{array}$ & Eq. & $\begin{array}{l}\text { ME, FA, BI, } \\
\text { QU, OC, GE }\end{array}$ & Médico,Guía. & An. & $\begin{array}{l}\text { Histórico, geomo r- } \\
\text { fología. }\end{array}$ \\
\hline $\begin{array}{l}\text { GranMuralla } \\
\text { (Chi) }\end{array}$ & 1985 & $\begin{array}{c}14 \\
2 \\
\end{array}$ & $\mathrm{C} / \mathrm{A} / \mathrm{D} 3$ & Ex. & GE, BI, AT & Tienda, Grúa. & An. & --- \\
\hline $\begin{array}{l}\text { Maldonado } \\
\text { (Ecu) }\end{array}$ & 1985 & 2 & -- & De. & -- & -- & Esp. & Geomorfología \\
\hline $\begin{array}{l}\begin{array}{l}\text { Artigas } \\
\text { (Uru) }\end{array} \\
\end{array}$ & 1985 & $\begin{array}{c}10 \\
1 \\
\end{array}$ & $\begin{array}{c}\mathrm{B} / \mathrm{C} \\
4 \\
\end{array}$ & Eq. & ME, IO, BI & $\begin{array}{l}\text { Tienda, Heli- } \\
\text { cóp., Meteo. }\end{array}$ & An. & $\begin{array}{l}\text { Geomorfología, } \\
\text { fauna. }\end{array}$ \\
\hline $\begin{array}{l}\text { King Sejong } \\
\text { (Cor) }\end{array}$ & 1988 & $\begin{array}{l}8 \\
2 \\
\end{array}$ & $\begin{array}{l}\mathrm{S} / \mathrm{B} \\
2-4 \\
\end{array}$ & Eq. & $\begin{array}{l}\text { GF, ME, } \\
\text { OC, GE, BI }\end{array}$ & & An. & \\
\hline $\begin{array}{l}\text { Juan Carlos I } \\
\text { (E) }\end{array}$ & 1989 & $\begin{array}{l}8 \\
1 \\
\end{array}$ & $\begin{array}{c}\mathrm{B} \\
4-1 \\
\end{array}$ & Ex. & $\begin{array}{l}\mathrm{BI}, \mathrm{GE}, \mathrm{GL}, \\
\mathrm{OC}, \mathrm{ME}\end{array}$ & & Estiv. & $\begin{array}{l}\text { Vegetación, geo- } \\
\text { morfología. }\end{array}$ \\
\hline $\begin{array}{l}\text { Machu Pichu } \\
\text { (P) }\end{array}$ & 1989 & $\begin{array}{l}4 \\
0 \\
\end{array}$ & $\begin{array}{c}\mathrm{B} \\
2-4 \\
\end{array}$ & Exp. & BI & & Estiv. & --- \\
\hline $\begin{array}{l}\text { Gabriel de Cast. } \\
\text { (E) }\end{array}$ & 1993 & $\begin{array}{l}6 \\
1 \\
\end{array}$ & $\begin{array}{l}\mathrm{D} \\
3 \\
\end{array}$ & Ex. & BI, GE, SI & Médico & Estiv. & $\begin{array}{l}\text { Geomorfología } \\
\text { volcánica. }\end{array}$ \\
\hline $\begin{array}{l}\text { St.Kliment } \\
\text { (Bul) }\end{array}$ & 1997 & 22 & $\begin{array}{c}\mathrm{C} / \mathrm{D} \\
1 \\
\end{array}$ & Ex. & GE, BI, ED & Médico & Estiv. & Geomorfología. \\
\hline
\end{tabular}

(1) Año de instalación y renovación; (2) $\mathrm{N}^{\circ}$ de edificios total y los destinados a investigación científica;(3) A, construcción en madera. B, contenedores. C, ecléctica. D, prefabricado en fibras. 1, compacto, 2, lineal.3, disperso-caótico, 4, planificado; (4)De, deterioro. Ex, expansiva. Eq, equilibrio. (5) GE, geología. SI, sismologái, VO, volcanología. BI, biología. HI, hidrología. ME, meteorología. GL, glaciología. OC, oceanografia. IC, icebergs. FA, física del aire. QU, química. AT, atmósfera. IO, ionosfera. GF, geofísica. ED, edafología. (6) Elementos más sobresalientes de la base y su entorno inmediato, respecto a las zonas deglaciadas donde se ubica. Señalar que el valor paisajístico, sobre todo glaciar, es alto para todos los asentamientos.

POUPIN Y BURGOS (1994). En las Shetland del Sur han influido la habitabilidad de un archipiélago con numerosos espacios libres de hielo, bahías y fiordos resguardados; la accesibilidad, dada la proximidad al cono sur americano y la ausencia de mar helado gran parte del año, y los bajos costes derivados (barcos sin equipamientos especiales, fondeaderos, proximidad al continente americano y antártico....), al menos en comparación con los sectores oriental y de Ross; los inte- 
reses geopolíticos y geoestratégicos; y, finalmente, los intereses científicos, a menudo dirigidos por las necesidades logísticas. Otro factor, como la presencia del aeropuerto Marsh, apunta también a la proliferación de bases. Su influencia es sobre todo de carácter local, responsable de que en el interior del archipélago el $60 \%$ de las bases, y las de mayor tamaño, se concentren en la isla Rey Jorge.

En las islas Shetland del Sur en todos los casos las bases son de tipo marítimo, por su localización en el entorno del continente, pero también por la ubicación de todas las bases en las zonas libres de hielo de las costas en lugares apropiados para el desembarco y el fondeado de buques y embarcaciones. La mayoría de ellas (88\%) se ubican en los niveles de playas levantadas y escalonadas que constituyen las porciones playeras de las costas del archipiélago. De las restantes tan solo Decepción (Arg.) se ubica en una cuenca lacustre de un antiguo cráter y Gabriel de Castilla, en la misma isla, en un glacis procedente de la ladera de un cono volcánico. Todas ellas se localizan al borde del mar, entre los 6 y los 25 metros de altura sobre el mismo.

La base constituye la vivienda y el lugar de trabajo de los habitantes antárticos, por lo que tiene vital importancia en el desarrollo de la actividad antártica. Pero también posee un papel paisajístico y se inserta en el ecosistema mediante la alteración del entorno y la intromisión de sustancias muy variadas. Pero primordialmente, en la base se desarrolla la vida antártica, en particular para las de invernada, donde durante los meses de invierno prácticamente la actividad cientifica dominante es de "observatorio", dedicada al registro de datos o a la observación sistemática, que se realiza desde el interior de las bases. Toma importancia, pues, la distribución de las bases, unas respecto a otras, las tipologías y elementos constructivos, que hacen cómoda o incómoda una estancia, obligan a mayor o menor dedicación, o permiten un cierto confort. Finalmente la disposición de los edificios, el tipo de plano, tiene implicaciones intrínsecas, de orden y comodidad para los usuarios de la base, y extrínsecas, en relación con su inserción en el paisaje antártico y el impacto que ejercen sobre el medio.

Su organización interna se realiza en casi todos los casos mediante la búsqueda de unidad en su funcionamiento y uso, para lo que siguen los principios de los barcos y la vida en el mar, tanto en su estructura y organización interna como funcionamiento. Este es un hecho común y a menudo el personal de apoyo forma parte de las respectivas armadas nacionales o son marinos profesionales, es el caso de bases como Decepción, Jubany, Cámara, Artowski, Ferraz, King Sejong o Juan Carlos I. El otro modelo más difundido es el modelo de cuartel militar, peor adaptado al aislamiento antártico y que conlleva variaciones tanto en los modelos constructivos y de plano como en los de comportamiento. Es el caso de FreiMarsh, Artigas, Machu Pichu o Gabriel de Castilla.

La localización (subantárica, marítima, cotinental), el tipo constructivo, el tipo de plano, la dinámica de la base (estable, expansiva o en abandono), su función (político-militar, logística, científica) y el periodo de utilización (estival o anual), constituyen los elementos clave que permiten definir a cada base antártica y establecer una síntesis, dentro de la individualidad de cada una. 


\subsection{Tipos constructivos: la adaptación al medio.}

Se han estrablecido tres tipos básicos de base, en los que se registran variaciones múltiples. En la tabla se ha numerado con el tipo principal, estableciendo un segundo número para las variaciones secundarias.

a) Construcciones en madera: barracones. Construcción típicamente ártica de los años cincuenta y sesenta que forma parte de las bases más antiguas. La técnica constructiva básica es la de un cinturón de hormigon que eleva y aisla el recinto, sobre el que reposa la estructura de madera ${ }^{7}$. La techumbre en madera a dos aguas, presenta técnicas variadas. Es una edificación confortable, pero que requiere un elevado coste, y un trabajo complejo (hormigonado, montajes,...), así como, una vez instalada, un mantenimiento intenso. Su abandono puede llevar a su rápido deterioro, aunque la madera no sufre ningún tipo de deterioro biológico. El hormigón, si no es de calidad, tiene una vida más limitada y requiere mantenimiento. Son construcciones inspiradas en las instalaciones militares, casi siempre adaptadas a las necesidades antárticas. Un buen ejemplo son las bases argentinas, nacidas como destacamentos navales (Decepción, Jubany, Cámara), que aunan la vida en un solo edificio, distribuyéndose en areas diferenciadas la vida y el trabajo, unidas por las zonas comunes de cocina y comedor. Decepción, la primera, constituye un modelo único, con un plano digitado en donde trabajo y común se organizan en una estancia de la que parten tres ramales, destinados a vivienda, que permiten una organización por categorías, reproduciendo el modelo en pisos de los barcos militares. Esta organización permite la unidad espacial del edificio, para los cambios de actividad, y mantener el rigor jerárquico. Las más sencillas tratan de mantener la unidad del edificio, pero sin la capacidad de separar jerarquías, modelo más parecido a los barcos de pequeño tamaño. En Frei, el origen es similar, si bien la complejidad urbanística de la base ha hecho que el conjunto sea muy diferente y se mezclen tipos y técnicas constructivas variadas.

Una variación a este modelo es el establecido desde los años setenta: el cinturón de hormigón es sustitudo por pilones del mismo material construidos mediante el relleno de bidones metálicos, que elevan y aislan el edificio con menos costes y complicaciones geotécnicas. Es el caso de Artowski. Los edificios complementarios siguen la misma tipología, pero con una mayor simplicidad en el plano.

Estas bases responden a un periodo histórico, el de los primeros asentamientos, que englobaría las bases, hoy abandonadas, británicas (B y G) y chilena (Decepción). Se construyen hasta los años 50 , con continuidad en modelos más evolucionados en los sesenta-setenta, en Bellinghausen, Frei y Artowski. Los costes de mantenimieno son un problema para su conservación, como se ha puesto de relieve en la renovación de la base de Decepción (Arg) en su cincuenta aniversario. En la actualidad constituyen el $25 \%$ de las bases, con presencia de esta construcción en tres bases más (Gran Muralla, Frei y Bellinghausen).

b) Contenedores: A finales de los setenta se impone un nuevo modelo cons-

\footnotetext{
${ }^{7}$ La estructura de madera es, como es sabido, muy peligrosa frente a los incendios, pero las demás técnicas y los aislantes sintéticos actuales también lo son, de modo que no establecemos diferencias en función de su capacidad combustible, pues en todos los tipos es alta y la peligrosidad elevada.
} 
tructivo, el de los contenedores. Los contenedores para el transporte mixto en camiones y barcos revolucionaron los transportes de carga y se aplicaron rápidamente para las construcciones provisionales de las empresas constructuras, extractivas o mineras, instalándose en su interior vestuarios, oficinas, salas y alojamientos. Este método se impone en el ártico y existen empresas especializadas para su acondicionamiento interior. Con pocas adaptaciones, este modelo constructivo se implanta en las bases, primero como refugios más o menos provisionales, después como construcciones auxiliares (almacenes, laboratorios, estaciones de control, etc.) y finalmente como módulos habitables. La facilidad del transporte en los barcos, donde también se han acondicionado en muchos casos (Las Palmas, Hespérides) como complemento, el acondicionamiento en los países de origen para transportarlos ya montados reduciendo las labores sobre el terreno, las facilidades del desplazamiento en tierra (grúas, patines) y la posibilidad de ensamble para construir módulos con contenedores agrupados, ha hecho que este sistema se haya utilizado con mucha frecuencia. Es difícil en la actualidad no encontrar ninguna base que no disponga de algún edificio construido mediante contenedores.

El acondicionamiento interior es muy variable en función de su uso y de la capacidad económica de cada programa de investigación. Modelos ejemplares son la base Ferraz, construida por acumulación de contenedores que forman un amplio edificio en el que se han acondicionado, en torno a un patio central techado, los laboratorios y las viviendas, como camarotes de barco. De dimensiones más modestas, la base Juan Carlos I, auténtico puzzle de contenedores engarzados complementados con un atrio en madera, han conseguido en poco espacio la máxima habitabilidad y confort en el módulo vivienda y utilidad en el módulo científico. Otras concepciones integradas se han desarrollado en Artigas, con módulos laboratorio-vivienda por cada especialidad, menos útiles para la calidad de vida por su desconexión del resto de la base. El acondicionamiento interno dependerá de las costumbres (militares, marineras, civiles, culturales...) y son muy numerosas las variables.

Destaca por su importancia en la arquitectura antártica la Villa de las Estrellas, porción de la base Frei-Marsh destinada al alojamiento de las familias de miembros de la base militar. Se trata de un conjunto de contenedores y prefabricados que alojan dependencias colectivas, el banco, correos, el hospital, la escuela y una iglesia de arquitectura antártica verdaderamente "singular". Las viviendas presentan mayor complejidad y constituyen un prefabricado con base en contenedores. Este es el complejo más "urbano" del archipiélago, y los contenedores se han ajustado a las necesidades de servicios que complementan el "barrio" residencial de la base.

En la actualidad este tipo constructivo, parcialmente abandonado desde mediados de los noventa, configura el $30 \%$ de las bases y está presente en tres más, formando parte de la mitad de las bases de las Islas Shetland del Sur.

c) Construcción de obra ecléctica: Muchas bases han optado por la adaptaciones de construcciones corrientes mediante cambios en las técnicas o los materiales. Así podemos observar una amplia gama de galpones, naves o pabellones en los que alternan o se combinan el metal, la madera y la mampostería. Destacan las construcciones metálicas, sobre cinturones de hormigón, que siguen los 
cánones de las construcciones industriales baratas urbanas o construcciones en metal y madera sobre estructuras metálicas (Bellinhausen), así como prefabricados de hormigón en combinados a menudo difíciles de clasificar. En algunos casos son construcciones habituales de mampostería, como la base St. Kliment (Bulgaria), construcción de tipo urbano. Estas edificaciones son dominantes en unas pocas bases, la mencionada, Bellinhausen (Rusia), la parte antigua de Gran Muralla (China) y King Sejong (Corea del Sur). La base Gran Muralla (China) fue construida por más de seiscientos obreros en una sola campaña, con edificios ecléticos pero pensados para el medio antártico y una abundancia de medios y mano de obra que permitía soluciones muy diversas. Los resultados no han sido buenos, pues la vida útil no ha superado los diez años de vida. Bellinghausen, en sus más de treinta años, también ha sufrido renovaciones constantes que denotan un carácter efímero de las instalaciones, quizás acusado por el abandono y mínimo mantenimiento desde inicios de los noventa.

En términos generales denotan tres tipos de actitudes. Planes con importantes medios, capaces de desarrollar construcciones complejas sobre el terreno, como es el caso de Bellinghausen y Gran Muralla; una modestia de medios, y adaptación a las posilidades de acceso a materiales sencillos, caso de St. Kliment; o una tecnología más avanzada, acompañada de altos presupuestos, para el caso de Corea del Sur. Esta base tiene edificios metálicos sobre estructuras metálicas de un perfecto acabado externo e interno. Son, pues, muy variables las aplicaciones de este tipo constructivo, en función de los condicionantes de cada programa nacional. Su representatividad es pequeña, sólo en tres bases, aunque está presente en un 30\% de las bases del archipiélago.

d) Prefabricados en fibra: Las técnicas más recientes se han decantado por los paneles de fibra con aislantes sintéticos intermedios montados sobre estructuras metálicas que los separan y aislan del suelo. El modelo se inspira en los modos de transporte y montaje de cuarteles y dependencias militares de campaña y semifijas, así como la arquitectura en el ártico, donde el permafrost impide asentar cimientos. Las facilidades para el transporte de los paneles y accesorios, la sencillez y rapidez de montaje, previa preinstalación en los países de procedencia, y la duración y bajo mantenimiento de los materiales, hacen de ellas el futuro de la construcción antártica. Estas técnicas se han aplicado a las bases ya existentes en las renovaciones y nuevas construcciones. Son ejemplares la ampliación de la base Gran Muralla, con un edificio en altura de grandes dimensiones (dos plantas), contruido en 1996, que ha sustituido a la mayor parte de las obsoletas instalaciones del 85. También, aunque en tamaño más modesto, son de este tipo constructivo la base Gabriel de Castilla (1993-1998) y las dependencias del INACH en Frei-Marsh, edificio polivalente amplio y moderno que sustituye a las viejas instalaciones y fue inaugurado en 1997. Todas ellas son de los años noventa y se están incorporando a las bases o refugios preexistentes, constituyendo el futuro inmediato de las construcciones en la Antártida marítima. Su representatividad actual es reducida, sólo una base tiene estas característica, aunque los complementos de este tipo están presentes en Jubany, Frei y Gran Muralla, siempre en las construcciones más recientes.

En resumen, podemos establecer que los cuatro tipos constructivos responden a la coyuntura de cada programa nacional y a los avances históricos y técnicos, 
de modo que en una evolución desde la madera a las fibras artificiales, se puede encontrar una amplia variedad tipológica de soluciones constructivas.

\subsection{La organización interna: los tipos de planos.}

El plano de las bases responde a la presencia de un medio hostil, el aislamiento y la imposibilidad de suministros, la historia del asentamiento y los condicionamientos económicos, políticos y culturales de los programas nacionales. Hemos establecido cuatro tipos principales de planos:

a) Compacto: Se trata de bases cuyos edificios se aglutinan unos junto a otros, constituyendo un todo continuo. En general son pequeñas, de modo que habitación, cocina comedor y zona de trabajo están muy próximas (Coopermine, St. Kliment, Cámara). En algunas hay elementos dispersos en el entorno del núcleo principal. Representan en total un $25 \%$ de las bases del Archipiélago.

La más representativa es Ferraz, con un núcleo denso que aglutina, mediante un sistema de contenedores y techados, todas las dependencias en un amplio espacio, de modo que no es necesario salir de la base para utilizar las distintas dependencias. Sólo son la excepción algunos observatorios del entorno de la base. Esta organización es muy práctica y sigue los principios de las bases continentales (Halley, Amundsen-Scott).

b) Lineal. Los planos con edificios alineados se generan en bases pequeñas, $o$ excepcionalmente, en Jubany, donde la topografía ha condicionado la localización de la mayoría de los edificios a lo largo de la línea de costa. Algunos edificios esparcidos sin orden rompen el plano, pero las nuevas instalaciones alemanas mantienen esta tendencía, favorecida por la estrecha rasa marina en la que se ubica. El resto, son pequeñas bases en las que los edificios se han alineado, es el caso de Machu Pichu o Artowski. Son muy poco representativas en el conjunto del las Islas Shetland del Sur (19\%).

c) Disperso-caótico: Se trata de bases sin organización aparente, cuyo plano responde a la construcción azarosa y en función de los intereses de cada momento, sin responder ni a planeamiento ni a condicionamientos. Las grandes bases tienden a organizarse de modo disperso y caótico, como resultado de las diferentes fases de construcción. Denotan a menudo una improvisación, sobre todo en las de menor tamaño, o una antigüedad en la que se superponen diferente planes de crecimiento. Representan un $25 \%$ de las bases del archipiélago.

Los mejores ejemplos son las bases de Bellinhausen y Frei-Marsh. Instaladas en 1968 y 69 respectivamente, han conocido una sucesión de fases de crecimiento y renovación, la base Frei en mayor medida. Ambas suman una aglomeración de 58 edificios en los que es posible diferenciar distintas unidades. Por una parte la base Bellinhausen, al norte del arroyo, presenta una absoluta dispersión de edificios, hoy sin mantenimiento y en estado de abandono, pues es una base concebida para más población que la actual. Los edificios, dispersos y alejados, configuran un espacio desarticulado. Al sur, se ubica la Base Frei, con un núcleo inicial, también disperso, formado por el edificio original de la base y la comandancia, junto a la Estación Científica Fildes del INACH, hoy base Prof. Julio Escudero (INACH), donde nuevos edificios estan densificando el plano. Hasta los años ochenta posee todo el conjunto un crecimiento disperso y caótico. En 1980 se 
inaugura el aeródromo Marsh, con una pista de 1.300 metros de longitud y su equipamiento además de una hospedería que funciona desde 1981. En este momento queda un nuevo núcleo desgajado y enlazado por una carretera, a lo largo de la cual crecen más dependencias del aeródromo. En 1984 se inaugura la Villa de las Estrellas, para alojar a las familias de los oficiales de la base, con todos los servicios necesarios para la vida cotidiana. Esta porción se organiza en torno a un ámbito central, o plaza, limitada por los servicios principales, la jefatura de la base, la tienda, el banco, el hospital y la escuela, a partir del cual, ladera arriba, se alinean las viviendas, que en 1997 alojaban a 51 personas. Es la actuación planificada más importante, continuando su crecimiento con un polideportivo y el nuevo edificio de la base Escudero, ya sin planeamiento ninguno. Podemos considerar a la aglomeración Bellinhausen-Frei la capital de las Shetland del Sur, pues a su tamaño suma su función de servicios (helicópteros, vehículos, comunicaciones, sanidad) para otras bases de las Shetland del Sur, y es la vía de entrada de gran número de científicos y turistas en el archipiélago, funcionando como lugar central para las bases dispersas por la isla. También forma parte de este grupo la base Gabriel de Castilla, si bien las dimensiones son más moderadas. Tiene su origen en el refugio del mismo nombre, compuesto por el módulo vivienda y tiendas de campaña, y posteriormente se han instalado de modo sucesivo cuatro edificios, almacén, despensa, módulo científico y módulo de motores, en tamaños y disposiciones variadas, sin planeamiento alguno, y que determinan el futuro crecimiento.

d) Planificado: Se trata de bases en las que se ha planificado la disposición de los diferentes edificios, de modo que se obtenga el máximo rendimiento del espacio. El primer ejemplo es la base Decepción (Argentina), ya comentada, en la que se realiza un planeamiento sin alterar hasta la actualidad. Otros ejemplos son Artigas y King Sejong, en torno a un espacio central, que actúa como avenida o calle principal. A ambos lados se instalan edificios de trabajo, residencia o servicios colectivos, en un planeamiento simplista derivado de los campamentos militares. A pesar de la simplicidad el espacio se aprovecha y las canalizaciones de agua corriente o residuales responden a una organización en la que se insertan nuevas construcciones. Finalmente, la base Juan Carlos I, más pequeña que las anteriores, se articula en torno a un espacio central en el que se ordenan el acceso, el módulo científico, el módulo vivienda y los módulos de servicios (taller, almacén, residuos, ...), estos alineados ladera arriba. En estas bases el crecimiento esta condicionado por el planeamiento original, que desemboca en el ahorro de costes. Todas ellas se escalonan en altura aprovechando los diferentes niveles de playas levantadas. Bases planeadas son sólo el 19\%, si bien, en la actualidad, algún tipo o zona con planeamiento alcanza a casi la mitad de las bases $(43 \%)$

\subsection{La población de las bases.}

Las bases de las islas Shetland del Sur están habitadas por científicos, técnicos y militares que representan la población del archipiélago. Las bases científicas poseen una población flotante que varía anualmente y estacionalmente (también por fases, o cada dos años, dependiendo de los destinos). Por tanto considero estas dotaciones como parte del poblamiento, es decir habitantes que utilizan un territo- 
rio, crean unas estructuras paisajísticas y territoriales y organizan el espacio en función de unas pautas culturales, de crecimiento y de densidad. Este último parámetro es muy poco útil en las Shetland del Sur, por ser un territorio sin población vernácula. En las islas Shetland de Sur, como territorio originariamente despoblado, no existe una adecuación territorial a las variaciones demográficas, sino que el número de habitantes responde a la planificación de cada base. La distribución de la población se adapta, de este modo, a la planificación y no es motor de cambios ni impulsa dinámicas territoriales propias. Sin embargo, esta población genera un poblamiento constante y posee una distribución en el archipiélago (CUADRO 3).

CUADRo 3. Población de las bases científicas de las Islas Shetland del Sur

\begin{tabular}{|c|c|c|c|c|c|c|}
\hline \multirow{2}{*}{ Base } & \multirow{2}{*}{$\begin{array}{c}\text { Capacidad } \\
\text { (1) }\end{array}$} & \multirow{2}{*}{$\begin{array}{l}\text { Dotación } \\
\text { Invierno } \\
(2)\end{array}$} & \multicolumn{3}{|c|}{ Dotación verano (3) } & \multirow{2}{*}{$\begin{array}{c}\text { Militares } \\
\text { (4) }\end{array}$} \\
\hline & & & Total & Apoyo & Ciencia & \\
\hline Prat & $?$ & 8 & 45 & -- & -- & SI- J,D+ \\
\hline Decepción & $65(505)^{*}$ & Esporádica & 7 & 4 & 3 & SI- D \\
\hline Jubany & $?$ & 12 & 60 & 19 & $4 * *$ & SI-J, D+ \\
\hline Cámara & 36 & Estival & 15 & 12 & 5 & SI-J, D+ \\
\hline Coopermine & $6-8$ & Esporádica & -- & -- & -- & NO \\
\hline Bellinghausen & -- & $?$ & 30 & $20-21$ & $9-10 * *$ & NO \\
\hline Frei-Marsh & -- & $20(+50)$ & $100(+50)$ & 100 & 6 & SI-J,D+ \\
\hline Artowski & -- & 20 & 20 & $?$ & $?$ & NO \\
\hline Ferraz & 50 & 20 & 49 & 14 & 35 & SI-J, D. \\
\hline Gran Muralla & 100 & 12 & 20 & 12 & 6 & NO \\
\hline Artigas & 40 & 12 & 30 & 25 & $5 * *$ & SI-J.D+ \\
\hline Maldonado & $?$ & Esporádica & $?$ & $?$ & $?$ & SI \\
\hline King Sejong & 45 & 15 & 45 & 12 & 3 & $\mathrm{NO}$ \\
\hline Juan Carlos I & 18 & Estival & 14 & 4 & 10 & NO \\
\hline Machu Pichu & $?$ & Estival & 40 & 39 & 1 & SI-J.D+ \\
\hline Gabriel Cast. & 16 & Estival & 15 & 7 & 8 & SI-J.D \\
\hline ST. Kliment & 7 & Estival & 7 & 4 & 3 & NO \\
\hline Total (5) & 718 & 169 & 537 & 272 & 99 & \\
\hline
\end{tabular}

(1) Fuente: informaciones de los Programas Nacionales, May (1989). * Capacidad total de la base. En la actualidad con uso esporádico.

(2) Fuente: Trabajo de campo 1997/99 y May (1989)

(3) Fuente: Trabajo de campo 1997/99. Estas cifras son todas aproximadas y pueden variar de un año a otro y a lo largo de cada campaña. De todos modos las consideramos indicativas de las dotaciones estivales de las bases. ** En Jubany no incluye investigadores extranjeros, que pueden elevar la cifra a 10-12 más (alemanes, italianos). En Bellinhausen y Artigas incluye investigadores extranjeros alojados en las bases.

(4) J, jefe de base militar. D, dotación militar (apoyo o científica). + dominio de la dotación militar.

(5) Cifras orientativas, pues cada año varían en cada base.

La variabilidad de las dotaciones, en función de los recursos económicos anuales, y los constantes cambios de capacidad en las bases, así como la interesada información de los programas nacionales hace que los datos sean en ocasiones poco reales. Los de verano se han obtenido mediante trabajo de campo, contrastado, cuando existe, con la información de las bases e institutos antárticos, durante las campañas 1996/97 y 1998/99, por lo que responde principalmente a la situación de estos años. 
La capacidad de las bases asciende a 718 habitantes, si bien raramente están al máximo de su capacidad. Una característica poblacional es la diferencia entre los habitantes de verano e invierno. En verano se triplica la población, pasando de aproximadamente 170 habitantes a más de 500. En invierno las bases se reducen al personal de mantenimiento y unos pocos técnicos y científicos que realizan observaciones, con números variables entre 8-12, para las bases medianas, y en torno a 20 en las mayores. En Frei-Marsh, la permanencia del aeropuerto y la presencia de familias eleva a cerca de 70 la dotación de invierno.

En verano la población supera los 500 habitantes. Esta cifra supone el 13\% de los habitantes científicos de la Antártida, si bien este se produce en un territorio muy reducido respecto al total del continente $(0,036 \%)$. Por presencia humana, este debe ser el segundo espacio, pues aunque no disponemos de datos, en función del número y el tamaño de las bases de la península Antártica esta debe superar en habitantes a las Shetland del Sur. En cualquier caso, la extensión de la península también es muy superior, de modo que las bases están más alejadas entre sí y sus habitantes, por tanto, más aislados.

Respecto a la densidad de población, las cifras no son comparables con otros espacios antárticos, pues este es en su mayoría un continente despoblado, y las bases se agrupan en unos pocos sectores de las costas. Es bien sabido que el significado de las densidades cambia en función de la escala y del medio físico y cultural, de modo que no se pueden obtener informaciones significativas. Para las Shetland del Sur la densidad sólo tiene valor si se calcula sobre la porción de tierras libres de hielo, lugar donde, como hemos visto, se ubican la totalidad de las bases del archipiélago. El resto son glaciares no ocupados por el hombre que implican una densidad no significativa $\left(0,114 \mathrm{hab} / \mathrm{km}^{2}\right)$. La densidad media de los espacios libres de hielo en las Shetland del Sur es de $1,14 \mathrm{hab} / \mathrm{km}^{2}$, y en determinados puntos desprovistos de hielo, como la península Fildes, la mayor aglomeración de bases de las islas (Gran Muralla, Frei-Marsh, Bellinghausen, Artigas), alcanza los 2,5 hab $/ \mathrm{km}^{2}$. Estas cifras son propias de territorios prácticamente despoblados, que indican una escasa presión sobre el medio. Pero la variabilidad es alta si se calculan en detalle, con densidades elevadas para bases pequeñas alojadas en reducidas zonas libres de hielo, el caso de Artowski, con densidades medias en verano de $175 \mathrm{hab} / \mathrm{km}^{2}$, y en invierno de $60 \mathrm{hab} / \mathrm{km}^{2}$ (RAKUSASUSZCZEWSKI, 1993).

Para unas tierras originalmente sin hombres y colonizadas por bases con dotaciones reducidas pero un potencial técnico muy elevado, ambas densidades implican una presión intensa. No es pues tan importante la cantidad de habitantes como la capacidad de alteración, en este caso muy elevada, en relación con la fragilidad del medio natural, en este caso también alta, lo que nos permite valorar la importancia de la población y su número en los espacios deglaciados de las islas Shetland del Sur.

Es significativa la distribución de dotaciones en las bases, si bien sólo disponemos de datos aproximados para el verano. En general, se observa que la dotación de apoyo casi triplica a la científica, de donde se deduce con facilidad que un $30 \%$ de los habitantes trabajan en la adquisición de conocimiento mientas el $70 \%$ restante se ocupa de tareas de mantenimiento, logística y apoyo científico. Este es un hecho significativo, pues hemos de tener en cuenta que en la mayoría de las 
bases el personal científico dedica una porción de su tiempo a las tareas colectivas (mantenimiento, apoyo, alimentación), con lo que el trabajo científico, objeto de la presencia de todas las bases en la Antártida, se reduce considerablemente en personal y tiempo. Finalmente, entre las características de la población destaca la existencia de un elevado número de personal militar. En más de la mitad de las bases (58\%) existe personal militar, y sólo en una de ellas el jefe de base no lo es. A ello hay que sumar que en seis bases (35\% del total de bases) la dotación militar supera a la civil. Por tanto, se constata que la presencia militar en el archipiélago es elevada, sobre todo por la capacidad dirigente de sus miembros, con cargos gestores en la mayoría de los casos, y en casi todos ellos dependientes de la autoridad militar (CUADRO 3).

Entre la población cabe destacar la perteneciente a la Villa de las Estrellas, de la base Frei-Marsh, donde viven una cincuentena de personas, entre ellas población infantil. No disponemos de la cantidad de niños o familiares que sin trabajar directamente en las bases viven en el poblado, y aunque no son significativos en número sí lo son en importancia. Este poblado se justifica como una necesidad para que el personal de invierno tenga más calidad de vida al poder contar con sus familias durante su estancia en la base. Aunque esto sea valorable, lo cierto es que surgió como contraposición a la base Marambio, donde Argentina llevó población civil y en 1978 nació la primera persona en el continente antártico ${ }^{8}$. Domina, pues, el interés político, y esto hace que además de niños y adultos no ligados a la actividad antártica, habiten en esta base banqueros, funcionarios de correos, médicos y maestros que atienden a esta pequeña población.

Las bases antárticas están sobredimensionadas, con un exceso de técnicos y personal de apoyo, que se complementan con las familias en la base Frei. Sin duda la reducción de las dotaciones y la tecnificación de las bases permitiría una mayor productividad científica con menos costes y agresividad ambiental. Se comprueba la contraposición entre el verano y el invierno, con una reducida presión invernal sobre el entorno de las bases, donde la escasa población queda prácticamente recluida, y la máxima presión estival, momento en el que se incrementa la presencia de científicos, visitantes de las bases y los turistas (SERRANO, 2001), que interfieren no sólo en el funcionamiento de las bases, sino del entorno.

\subsection{Función de las bases.}

El Tratado Antártico sólo admite la finalidad científica de las bases y asentamientos en la Antártida. Sin embargo, aunque en todas ellas se desarrollan programas científicos, un análisis de las labores y tareas a las que se dedica la dotación permite aproximarnos a las finalidades prioritarias de cada base. Casi todas ellas responden en su origen a fines políticos, pues siete de las diecisiete bases (41\%) permitieron acceder al rango de miembro consultivo en el sistema del Tratado Antártico. Este exige una actividad científica demostrada y se ha hecho habitual que esta actividad sea la presencia de una base y el uso de un buque de in-

\footnotetext{
${ }^{8}$ Emilio Marcos Palma fue el primer ser humano nacido en la Antártida, el 7 de enero de 1978. Le seguirían entre esta fecha y mayo del 83 otros ocho nacimientos, que Argentina utiliza como prueba de ocupación efectiva en sus reclamaciones territoriales.
} 
vestigación. Otras cuatro bases nacen como destacamentos navales (Prat, Decepción, Jubany y Cámara). Las restantes, tienen su origen en necesidades logísticas (Frei y Bellinhausen), o múltiples intenciones, desde la presencia física en el continente a los intereses científicos (Ferráz, Gran Muralla y Gabriel de Castilla). Su origen, pues, es político en un $76 \%$ de las bases instaladas en las islas Shetland del Sur. Sin embargo para juzgar su finalidad prioritaria actual no basta su origen, pues muchos países han cambiado su orientación desde la instalación de las bases.

El análisis de una serie de parámetros, tales como la procedencia de la financiación de las bases (militar, diplomática o científica), la dirección de las mismas (militar, civil, científica), el porcentaje de científicos entre las dotaciones, los objetivos y servicios ajenos a la investigación, y el tipo de investigación, permiten conocer el trabajo en las bases y los objetivos prioritarios (CUADRO 4).

CUADRO 4. Función de las Bases Antárticas.

\begin{tabular}{|c|c|c|c|c|c|c|c|}
\hline Base & $\begin{array}{l}\text { Origen } \\
\text { (1) }\end{array}$ & $\begin{array}{c}\text { Financ. } \\
\text { (2) }\end{array}$ & $\begin{array}{l}\text { Direc. } \\
\text { (3) }\end{array}$ & $\begin{array}{l}\text { Dot. } \\
\text { Cient. }\end{array}$ & $\begin{array}{l}\text { Serv. } \\
\text { Exter. }\end{array}$ & $\begin{array}{l}\text { Tipo in- } \\
\text { vest. (4) }\end{array}$ & $\begin{array}{c}\text { Categ. } \\
\text { (5) }\end{array}$ \\
\hline Prat & $\mathrm{M}$ & $\mathrm{M}$ & $\mathrm{M}$ & $<10 \%$ & SI & $\mathrm{O}$ & $\mathrm{M} / \mathrm{pp}$ \\
\hline Decepción & M & $\mathrm{AE}$ & $\mathrm{C}$ & $42 \%$ & $\mathrm{NO}$ & $\mathrm{T}$ & C \\
\hline Jubany & $\mathrm{M}$ & $\mathrm{AE}$ & M & $17 \% *$ & SI & $\mathrm{T}(\mathrm{O})$ & PP \\
\hline Cámara & M & $\mathrm{AE}$ & M & $29 \%$ & NO & $\mathrm{O}(\mathrm{T})$ & PP \\
\hline Coopermine & $\mathrm{M}$ & $\mathrm{AE}$ & $\mathrm{C}$ & -- & $\mathrm{NO}$ & $\mathrm{T}$ & $\mathrm{C}$ \\
\hline Bellinghausen & $\mathrm{L}$ & $\mathrm{C}$ & $\mathrm{C}$ & $31 \%$ & SI & $\mathrm{O}(\mathrm{T})$ & $\mathrm{L}$ \\
\hline Frei-Marsh & $\mathrm{L} / \mathrm{M}$ & $\mathrm{M}$ & $\mathrm{M}$ & $5,6 \%$ & SI & $\mathrm{O}$ & $\mathrm{L}$ \\
\hline Artowski & $\mathrm{P}$ & $\mathrm{C}$ & $\mathrm{C}$ & $?$ & $\mathrm{NO}$ & $\mathrm{T}(\mathrm{O})$ & $\mathrm{C}$ \\
\hline Ferraz & $\mathrm{C}$ & $\mathrm{AE}$ & $\mathrm{M}$ & $71 \%$ & $\mathrm{NO}$ & $\mathrm{O}(\mathrm{T})$ & $\mathrm{C}$ \\
\hline Gran Muralla & $\mathrm{C}$ & $?$ & $?$ & $33 \%$ & SI & $\mathrm{O}(\mathrm{T})$ & PP \\
\hline Artigas & $\mathrm{P}$ & $\mathrm{M}-\mathrm{AE}$ & M & $16 \%$ & SI & $\mathrm{O}(\mathrm{T})$ & PP \\
\hline King Sejong & $\mathrm{P}$ & $\mathrm{C}$ & $\mathrm{C}$ & $20 \%$ & $\mathrm{NO}$ & $\mathrm{O}(\mathrm{T})$ & $\mathrm{C}(\mathrm{pp})$ \\
\hline Juan Carlos I & $\mathrm{P}$ & $\mathrm{C}$ & $\mathrm{C}$ & $71 \%$ & $\mathrm{NO}$ & $\mathrm{T}(\mathrm{O})$ & $\mathrm{C}$ \\
\hline Machu Pichu & $\mathrm{P}$ & $\mathrm{AE}$ & M & $2,5 \%$ & $\mathrm{NO}$ & -- & PP \\
\hline Gabriel Cast. & $\mathrm{C}$ & $\mathrm{C}, \mathrm{M}$ & M & $53 \%$ & $\mathrm{NO}$ & $\mathrm{T}$ & $\mathrm{C}$ \\
\hline St.Kliment & $\mathrm{P}$ & $\mathrm{AE}$ & $\mathrm{C}$ & $42 \%$ & $\mathrm{NO}$ & $\mathrm{T}$ & PP \\
\hline
\end{tabular}

(1). M, militar. P, político. C, científico. (2). M, presupuesto militar. AE, presupuesto de asuntos exteriores. C, presupuestos cientificos. (3). M, militar. C, civil. (4). O, proyectos de observatorio. $\mathrm{T}$, proyectos sobre el terreno. (5). M, Militar. C, científica. PP, presencia política. L, logística.

El tipo de trabajo científico puede ser de dos tipos. Por un lado, programas de investigación basado en "ciencias de observatorio", y por otro, los proyectos realizados "sobre el terreno". En los primeros, el trabajo de campo consiste en el mantenimiento de observaciones rutinarias y el de gabinete en el envío a instituciones internacionales, tales como los observatorios ionosféricos, meteorológicos, control de icebergs, ozono, $\mathrm{CO}_{2}$. Estos trabajos tienen el valor de la obtención de datos globales y de su aplicación, para lo cual es necesario establecer redes sobre el terreno y grupos internacionales que trabajen con ellos. Sin embargo, los medios y dotaciones están predeterminados, y sobre el terreno se necesita un técnico 
en instrumentación u observación, sin la necesidad del desarrollo de equipos de investigación nacionales. Por el contrario, en la mayoría de estos proyectos es necesario el mantenimiento de bases abiertas durante todo el año, lo que encarece las investigaciones. En un porcentaje muy alto, y por limitaciones obvias, la investigación de invierno en las bases se limita a estos tipos de programas. Aunque posee pros y contras, muchos países se inclinan por este tipo de investigación, que de modo rápido y eficaz, aunque a veces con altos costes, permite insertarse en los grupos científicos internacionales. Por otra parte están los proyectos de campo propios, que aplican nuevas técnicas, desarrollan metodologías y aportan conocimientos globales y locales. Estos necesitan la creación y consolidación de grupos de investigación, lo que significa al menos unos años de puesta al día y rodaje en medios no habituales y hostiles que pueden conducir al fracaso, unas logísticas anuales variadas y una política científica más flexible y organizada.

En este sentido es interesante observar quien financia las bases y su expansión, pues denota el interés que se localiza detrás. Se obtiene una idea clara de la inclinación mayoritaria de las bases del archipiélago hacia programas de observatorio (el $46 \%$ de las que desarrollan investigación), que alcanza el $73 \%$ si se tiene en cuenta las bases que incluyen ambos tipos de programas de investigación. En las Shetland del Sur los institutos y programas que soportan las bases dependen de los presupuestos militares (Chile, Argentina, Perú), los ministerios de Asuntos Exteriores (INAH de Chile, IAA de Argentina, China, Bulgaria) o programas nacionales de ciencias (Academias de Ciencias, ministerios; Rusia, Polonia, España). En España, si el impulso inicial lo dio el ministerio de Asuntos Exteriores, junto a presupuestos militares, hoy prioritariamente dependen de los presupuestos de investigación científica y educación. Finalmente, otras bases no incorporan proyectos por su reciente llegada a la investigación en el continente o debido a la irregularidad de sus campañas de campo.

Los fines de las bases, en función de estos parámetros los podemos establecer en cuatro. Lo habitual es que en las bases se compaginen varias finalidades al mismo tiempo, con objetos científicos en todas ellas, por lo que resaltaremos la finalidad prioritaria y dominante.

a) Militar: En la actualidad no existen bases puramente militares, pues el Tratado antártico prohíbe la presencia de armamento en el continente. Sin embargo, los intereses nacionales implican la presencia, traducida en el apoyo logístico a los proyectos científicos, de los militares. Pero a pesar del cuidado en las relaciones diplomáticas, estados como Gran Bretaña, Argentina o Chile hacen notar siempre que pueden que los restantes investigadores se encuentran en su territorio. Las bases Prat y Frei-Marsh, con un dominio absoluto de personal militar y misiones fundamentalmente de control naval, están muy próximas a un cuartel en latitudes más bajas. La actividad científica se reduce a los registros metereológicos, realizados por militares, y están destinados, además de a la comunidad científica internacional, al apoyo a la navegación aérea y naval de los aviones y barcos militares.

b) Presencia política: El origen político-diplomático de la mayoría de las bases antárticas de las Shetland del Sur condiciona su funcionalidad en muchos de los casos. Las bases con proyectos de observatorio, dirigidas y gestionadas por militares, financiadas por instituciones diplomáticas, con escasa dotación científi- 
ca, menos del $20 \%$ en algunos casos, y servicios externos, responden a la necesidad de la presencia física en el continente con el objeto de mantener el peso político en los foros internacionales. Entre estas se encuentran bases medianas y grandes, con potentes instituciones antárticas dependientes de ministerios de asuntos exteriores. Es el caso de las bases Jubany, Cámara, Gran Muralla o Artigas. En otro caso están las bases menores y sin desarrollo, las más recientes, que sin adscribir a proyectos de observatorio, todavía no han incorporado conocimientos nuevos sobre aspectos a estudiar desde la Antártida o sobre la Antártida misma, y su presencia, en vías de consolidación, persigue ante todo la presencia física con objetivos políticos. En total suman el $41 \%$ de las bases instaladas en las islas Shetland del Sur.

c) Cientifica: Se trata de bases cuyo origen puede ser político, militar o derivado de los intereses y la politica científica de los programas nacionales. En ellas, la prioridad no es la presencia física para la obtención de peso político, que podría mantenerse mediante los buques oceanográficos o convenios con otros países, sino el mantenimiento de programas de investigación, ya sea mediante proyectos de observatorio o sobre el terreno. La dedicación de las mismas es variada, e incluye dotaciones con militares y sin ellos y financiaciones también diversas. Sin embargo, en todas ellas los servicios externos están restringidos y las dotaciones científicas son altas (más del 40\% salvo en King Sejong). Una visión a las publicaciones científicas permite ver que además de incorporar datos a las observaciones rutinarias sobre física y química de la atmósfera y los océanos, mantienen un alto nivel de calidad en las publicaciones. Las bases adscritas a esta categoría representan un $40 \%$, pero de estas, dos son de uso esporádico (Coopermine y Decepción) y otras dos sólo estivales (Juan Carlos I y Gabriel de Castilla).

d) Logística: Se trata de bases cuya localización y funcionamiento tienen como objetivo prioritario el apoyo logístico a los programas científicos o a la presencia político-militar. Las dos bases de esta categoría son Frei-Marsh y Bellinghausen, ambas ubicadas juntas, en el centro neurálgico de los servicios y las comunicaciones del archipiélago. En la bahía Maxwell estas bases gestionan un aeropuerto, préstamo de vehículos oruga, almacenamiento y avituallamiento de combustible, oficina de correos, hospital, tiendas, teléfono público y hospedería, que atienden tanto a otras bases y programas nacionales antárticos, como al turismo. En ellas la presencia política, los objetivos geoestratégicos y el apoyo a la ciencia se unen, dedicando a la investigación científica proyectos de observatorio.

\subsection{Dinámica de las bases.}

En la actualidad existen tres tipos de bases en función de los intereses políticos o científicos y de las capacidades de los programas nacionales, de modo que es fácil apreciar el futuro de las mismas. En una síntesis de la situación actual podemos diferenciar:

- En expansión, con renovación de antiguas edificaciones y construcción de nuevos edificios, las bases están en periodo de crecimiento. En esta situación se encuentran siete bases de las Shetland del Sur. Jubany mediante la participación de países europeos que invierten en laboratorios está en un proceso de expansión fundamentalmente de carácter científico, al igual que sucede en el Gabriel de Cas- 
tilla y Juan Carlos I, mal dimensionadas para el número de proyectos científicos que reciben cada año. Otras bases, como St. Kliments o Machu Pichu, se están instalando, por lo que su crecimiento es obligado para crear las condiciones que permitan asentar la investigación. Por el contrario, grandes bases como FreiMarsh o Gran Muralla están también en un periodo de expansión a partir de las necesidades logísticas y la renovación de instalaciones. En este caso la ampliación no incide en el nivel científico ni la calidad de las condiciones de investigación.

- En equilibrio: estables, no realizan nuevas construcciones ni abandonan el uso de edificios. Son bases que mantienen dotaciones y proyectos científicos más o menos estables, sin interés en crecer. Se trata tanto de bases grandes, Prat, Ferráz o King Sejong, de países que tienen las necesidades cubiertas en presencia o investigación, como bases menores, Cámara, o Coppermine, esta última con uso esporádico que obedece a programas de investigación continuos pero con campañas de corta duración.

- En deterioro, aquellas bases usadas esporádicamente o con menor dotación de la que pueden alojar, lo que conlleva un mantenimiento deficitario y el deterioro de las instalaciones. Estas bases corresponden a países en crisis, que mantienen sus instalaciones bajo mínimos, como Decepción y Bellinghausen, o cuya presencia es muy esporádica por su escasa inversión en la política antártica, como sucede en la base Maldonado. Argentina está solventando la inversión y mantenimiento mediante convenios con programas extranjeros (Polar Forschung Institute, UE, USA) que les permiten mantener bases abiertas e incluso en expansión. Sin embargo si estas carecen de interés, como sucede en Decepción, donde ha permanecido abierta en colaboración con investigadores españoles, las instalaciones están infrautilizadas. A esta base se le ha realizado una renovación, fundamentalmente externa, con motivo de los actos del cincuenta aniversario de su instalacón, pero esto no ha significado un incremento en su utilización.

En las islas Shetland del Sur existen un $18 \%$ en fase de deterioro, mientras que las equilibradas y las expansivas se igualan. Pero el $41 \%$ de bases en expansión denota un gran dinamismo de la actividad político-militar (pues el 70\% de esas bases están orientadas a la presencia político-militar), principalmente de países deseosos de mantener y acondicionar su presencia en la Antártida, así como un dinamismo científico derivado del ímpetu del personal por mejorar las condiciones y consolidar la investigación.

\section{IMPLICACIONES PAISAJÍSTICAS Y AMBIENTALES DE LOS ASENTAMIENTOS HUMANOS.}

La construcción de bases y la vida diaria en ellas, anual o estacional, significa la intervención sobre el medio físico y la organización por el hombre del espacio antártico en dieciséis áreas libres de hielo de la Antártida marítima, una intervención cada vez más capaz y técnica que desemboca en la alteración del paisaje en casi todas las bases y del equilibrio natural en todas ellas. Las bases implican alteraciones e impactos sobre el entorno, en los términos utilizados por SIMMONS (1996), sobre un medio donde el hombre se ha incorporado muy recientemente.

El impacto de las bases y las implicaciones ambientales ha sido un tema de preocupación constante por el SCAR, planteado formalmente en un informe de 
1985. Pero nada concreto se realizará hasta la firma del Protocolo sobre Protección Ambiental, conocido como Protocolo de Madrid. El artículo 3 desarrolla los principios medioambientales, que desde el año 1993 han supuesto cambios significativos en la organización y funcionamiento de las bases, encontrándonos todavía en la actualidad en fase de adaptación y aplicación del Protocolo. Pero uno de los elementos significativos ha sido la necesidad de gestionar las bases conforme a la conservación del medio y la capacidad del territorio, teniendo en cuenta tanto los valores ecológicos como estéticos y de uso científico (art.3). Este protocolo regula la realización de evaluaciones de impacto ambiental (EIA) para el desarrollo de proyectos de gran escala en la intervención sobre el territorio, lo que incluye cualquier tipo de construcción o renovación de bases (art.8). Las bases deben adaptarse a la nueva normativa en asuntos como la acumulación de restos y depósitos de basuras, su tratamiento y evacuación, o la utilización de productos que no resulten nocivos para el medio antártico (anexo III).

Las afecciones más comunes y los impactos que ocasionan sobre el medio son los siguientes:

a) Constructivas:

- Topográficas: Derivan de los movimientos de tierras para la construcción y la alteración de la topografía. Su impacto no es muy elevado en las Shetland del Sur, pues las bases son de pequeñas dimensiones y aprovechan en su mayoría los rellanos de las playas levantadas y escalonadas holocenas. Casi siempre el mayor movimiento de tierras procede de la instalación de depósitos y fosas sépticas. Sin embargo, en las bases más grandes y con construcciones complementarias, si es importante. Sobre todo en Frei-Marsh, donde la construcción del aeropuerto (pista, hangares, depósitos, etc) han supuesto la alteración topográfica de más de kilómetro y medio.

- Infraestructuras: Se trata de la construcción de pistas que unen las bases con edificios complementarios, o varias bases entre sí. En este sentido se han realizado pistas en la Península Fildes, donde Gran Muralla, Frei, Bellinghausen y Artigas están conectadas, aumentando la frecuentación por vehículos y personas, y su paso reiterado ocasiona impactos en los niveles sonoros, la calidad de las aguas, destrucción parcial de zonas encharcadas, destrucción de suelos e incremento de procesos erosivos, alternancia de compactaciones, congelamientos y saturaciones que alteran la estructura de suelos y depósitos, la destrucción de la vegetación e interferencia con la fauna. Los vehículos todo terreno de pequeñas dimensiones, para los cuales no se construyen pistas, generan nuevos caminos y pistas espontáneas. En la isla Decepción y en la Península Keller se están generando pistas espontáneas.

- Encauzamientos: Se trata de obras hidráulicas para la contención y desvío de las aguas. No son muy frecuentes y se limitan a tomas de aguas provisionales en casi todos los casos, sin generar impactos graves ni permanentes, pues las porciones de caudales también son reducidas.

- Geomorfológicas: La destrucción de formas de relieve significativas o cambios en los procesos dinámicos con pérdida de elementos singulares se centra principalmente en los sistemas de playas escalonadas mientras que en las zonas altas la frecuentación, a pie o motor, implica procesos erosivos nuevos y cambios geomorfológicos significativos a grandes escalas. 
- Edáficas: La destrucción y alteración de los suelos por compactación es moderada, pues no existen suelos bien desarrollados en las zonas libres de hielo. Sin embargo, su escasez hace que sea un elemento singular en niveles altos de playas y plataformas y por tanto más graves las consecuencias de su deterioro.

- De la vegetación: Las alteraciones de la vegetación significan su destrucción parcial o total por las actividades constructivas o de uso. En el medio antártico marítimo la vegetación es escasa y frágil, por lo que su alteración supone una pérdida muy importante. Los modos de afección son las pistas, las bases, el pisoteo en torno a la base y la recolección de líquenes y musgos como recuerdo, que esquilman especies de crecimiento muy lento. Las bases más grandes ya han deteriorado la escasa vegetación y es imposible su reconstitución.

- De la fauna: La instalación de bases implica la inmediata desaparición de las colonias y la degradación progresiva del entorno más o menos próximo. Es un hecho constatado la desaparición de las colonias de pingüinos de Fildes, en el sector de las bases, y el descenso de población de la isla Ardley. Por otro lado atrae a determinadas aves, como el págalo, con importantes cambios en sus costumbres y comportamiento en Frei, Bellinghausen, Artigas, King Sejong, y seguramente en otras muchas. Finalmente, la frecuentación del entorno de las bases afecta a colonias de nidificación, sometiendo a fuerte tensión a los nidos de pagalos, charranes, cormoranes o petreles, como ha sucedido con esta última especie en la Punta Thomas (isla Rey Jorge) junto a la base Artowski (RAKUSA-SUSZCZEWSKI, 1993).

- Paisajística: Aunque subjetivo, todos los elementos que alteren el paisaje, podemos afirmar que deterioran su valor estético y cultural. Dada la simplicidad del paisaje antártico, la alteración por el hombre es en sí un elemento indicador de impacto, pero a vecs los impactos paisajísticos pueden resultar insostenibles, pues las alteraciones llegan a transformar los elementos definitorios de su fisonomía. Esto es lo que ha sucedido en el paisaje deglaciado lacustre de la península Fildes, principalmente en la porción central, donde las aglomeración de bases ha creado un paisaje suburbial en total disarmonía con el entorno glaciar. Las bases de reducidas dimensiones, compactas o planificadas en un menor espacio, son las construcciones que menos impacto paisajístico ocasionan en la Antártida marítima.

b) Derivadas de su utilización:

- Contaminación: Las principales afecciones son los vertidos de las bases, hoy día en periodo de adaptación hacia las normativas del Protocolo de Madrid. Estos se vierten al mar o a los arroyos próximos causando contaminaciones y malos olores en tierra. Los residuos sólidos, acumulados en el entorno de las bases, con fuertes impactos ecológicos y estéticos deben ser evacuados del continente, pero el encarecimiento y la cantidad de los mismos hacen que a menudo se tomen medidas alternativas. Las importantes acumulaciones de chatarra en las bases, sobre todo en las más grandes, han obligado a una adaptación antes de aplicar el protocolo de Madrid. Es paradigmático el ejemplo de Bellinghausen, donde han enterrado chatarra en una amplia zona para empezar de cero con la evacuación de la producida en periodos recientes, con la remoción de más de $500 \mathrm{~m}^{2}$ de terreno que ha altarado la circulación hídrica, los procesos geomorfológicos y la fauna, en un medio de difícil regeneración. 
Los vertidos de los barcos de apoyo, unidos a los anteriores, deterioran los ecosistemas costeros, en particular en zonas de tránsito como las bases mayores o los depósitos de combustible que se alimentan desde los buques. En este sentido, vuelve a ser la bahía Maxwell el sector costero que soporta mayor presión.

- Cambios de caudales: Afectan al tratamiento de las aguas de ríos y arroyos del entorno de las bases, principalmente a los lagos próximos, de los que se alimentan muchas de las bases. Hoy día la zona más afectada, anteriormente lugar especialmente protegido, son las cuencas lacustres de Fildes, Bellinghausen, Frei, Artigas y Gran Muralla, aunque el sistema se está generalizando y se aplica en otra bases como Gabriel de Castilla, Juan Carlos I, Jubany o King Sejong.

- De la fauna: En las zonas libres de hielo el hombre entra en competencia directa con la fauna por el espacio físico. Ya hemos expuesto como la alteración directa afecta a la fauna, pero la frecuentación de playas, desembarcos, visitas y paseos implican la alteración de los ritmos vitales de colonias e individuos. En general, el impacto mas generalizado es el paulatino abandono de zonas de cría y nidificación en torno a las bases, con los ejemplos ya señalados de Fildes, Ardley y Punta Thomas.

- Emisiones atmosféricas: Afecta a casi todas las bases, principalmente por la incineración de residuos orgánicos y el uso de combustibles sólidos para el mantenimiento de las bases. El primer caso no se debe ya producir, pues ha sido prohibido por el protocolo de Madrid (anexo III, art.3), y las emisiones de este tipo, que todavía existen, son puntuales. En el segundo caso, las emisiones continuarán, pues la incorporación de energías limpias es lenta y problemática en un lugar aislado y es de lógica que se impongan en las bases cuando se generalice su uso en las sociedades y naciones a las que pertenecen. Es necesario resaltar el papel experimental que tienen muchas bases en la aplicación de nuevas tecnologías a la construcción en medios hostiles, si embargo este aspecto debería potenciarse, pues a menudo se utilizan técnicas obsoletas y altamente contaminantes.

- Frecuentación del entorno: Finalmente, aunque ya se han comentado sus efectos, resaltar como la frecuentación del entorno de las bases para trabajos científicos (campo, laboratorios, parcelas experimentales, etc), usos complementarios (residuos, laboratorios, tomas de agua, etc) o el necesario esparcimiento de las dotaciones (paseos, excursiones en fin de semana) es una afección importante. Las bases de menor población ejercen menos presión sobre el entorno que las grandes, de modo han de tenerse en cuenta en la evaluación de impactos de las bases y en la planificación de las mismas las alteraciones derivadas de la frecuentación y sus efectos efectos secundarios.

\section{CONCLUSIONES.}

- La configuración actual de la red de asentamientos responde a una concepción geoestratégica y militar,con instalaciones militares y dirigidas por los ministerios de Asuntos Exteriores, hasta los años setenta, cuando la apertura de las condiciones políticas propicia la inclusión de nuevos miembros al Tratado Antártico. Todas ellas responden a intereses políticos y geoestratégicos, de modo que la investigación es secundaria. Las más grandes, Bellinghausen y Marsh, tienen funciones logísticas, y su localización está determinada por la posición del archipiéla- 
go. Las restantes se apoyan o se han apoyado en sus inicios en la logística de estas bases, así como en las facilidades que aporta una baja latitud para la navegación y las comunicacones con América.

- Las aportaciones científicas y técnicas son muy variables. Por un lado se trata de países nuevos que necesitan introducirse en el ámbito de la investigación antártica para empezar a realizar aportaciones, y tienen dificil competir con países avezados en los estudios polares. En los restantes estados, si a su inexperiencia se suman la dominante militar en las bases, se obtienen resultados desiguales, con países en los que se realizan rápidos progresos, Polonia, Brasil, Corea del Sur o España, y otros que, centrados en la logística, no sostienen programas capaces de aportar estudios significativos sobre el medio en el que se localizan, si bien se asocian a redes de registros meteorológicos (Artigas, Marsh), de $\mathrm{CO}_{2}$ (Jubany) o a países con fuerte potencial investigador (Alemania, Holanda, USA, etc.).

- Las bases antárticas de las islas Shetland del Sur constituyen asentamientos muy heterogéneos tanto por su tipología, como finalidad. Los modelos se adaptan a los momentos históricos en que fueron construidos, y esta variedad permite comprobar la utilidad e idoneidad de cada tipo. Los cuatro planos definidos responden a la historia y visicitudes de los programas antárticos nacionales, y a la evolución de las bases, con una fuerte influencia de la improvisación, si bien existe una tendencia al orden para ahorrar esfuerzos y gastos, así como ganar comodidad.

- Las bases están sobredimensionadas, con un exceso de técnicos y personal de apoyo, de modo que la reducción de las dotaciones y la tecnificación de las bases permitiría una mayor productividad científica con menos costes y agresividad ambiental. Destaca la fuerte presión estival, con un incremento de científicos, visitantes y turistas.

- Las alteraciones e impactos de las bases de las Shetland del Sur poseen una entidad regional, afectando a espacios puntuales, pero sin repercusiones continentales ni globales, quedando limitados a daños de los ámbitos deglaciados del archipiélago. Estos se concentran en las zonas libres de hielo, que por su escasez hacen que tengan mayor importancia. Sólo el sector central de Fildes posee un elevado impacto ambiental y paisajístico derivado de las construcciones y los usos actuales (aéreos, almacén de combustibles, bases, comunicaciones, suministros de agua, residuos, etc...).

- Las bases de tamaño menor, donde la relación entre científicos y personal de apoyo es favorable a los primeros, muy tecnificadas en medios logísticos y científicos, y apoyadas con asiduidad por medios externos (buques logísticos y científicos capaces de evacuar deshechos y aportar suministros), son las de menor grado de impacto sobre el entorno y tienen más facilidad para controlar las afecciones. Este es el modelo de futuro para la investigación antártica en una "reserva natural destinada para la paz y para la ciencia" (art. 2, Protoco de Madrid).

\section{BIBLIOGRAFÍA.}

- ARAMAgO, C. (1949): Historia de la Antártida.. Buenos Aires.Ed. Hemisferio

- CAlvo, A. (1992): La Antártida. Catedral del hielo. Madrid.McGraw-Hill. 
- Castellví, J. (1996): Yo he vivido en la Antártida. Madrid. Círculo de Lectores.

- HEADLAND, R.K. (1989): Chronological list of Antarctic expeditions and related historical events. Studies in Polar Research. Cambridge. Cambridge University Press. Caralt.

- KIRWAN, L.P. (1965): Historia de las exploraciones polares. Barcelona.

- LÓPEZ MARTíNEZ, J. (1998): «La frontera sur del planeta. España en los mares antárticos", en Foro de debate sobre el mar y sus problemas, Madrid, Sociedad estatal Lisboa 98, pp. 347-366

- LÓPEZ MARTíNEZ, J. (2000): «La investigación científica y el medio ambiente en la Antártida. Estructura de la actividad antártica espa_ola», en Aproximación estratégica espa ola a la última frontera: La Ántártida. Monografías del CESEDEN, $\mathrm{n}^{\circ} 3 \overline{7}$. Madrid. Centro Superior de estudios de la defensa Nacional, pp. 21-60.

- MACKENZIE, G. (1988): «The Austral Crescent», Antarctic Journal of the United States, 23(4) pp. 7-13.

- MARTíNEZ DE PISÓN, E. Y CASTELLVÍ, J. (1993): «La investigación científica en la Antártida», Cuadernos Jurídicos, 12, pp. 52-55.

- MARTíNEZ DE PISÓN, E. (1991): «La Antártida, un continente sin dueño», Cuenta y Razón, ${ }^{\circ}$ 56-57, pp. 129-131.

- MAY, J. (1989): El libro GreenPeace de la Antártida. Barcelona. Green Peace.

- NogueIRA, C. (1997): Viaje a la Antártida. Vida y secretos de un continente amenazado. Madrid.Alianza editorial.

- POUPIN, M., BURGOS, L. (1994): «Asentamientos antárticos, un desafío para la relación sociedad-naturaleza», Boletín Anártico Chileno INACH, vol. 13 $\mathrm{n}^{\circ} 2, \mathrm{pp} .2-7$.

- PURI, R. (1997): Antarctica. A natural reserve. A study in international environmental politics. Shimla. Indian Institute of advanced study.

- RAKUSA-SUSZCZEWSKI, S. ED. (1993): The maritime antarctic cosatal ecosystem of Admiralty bay. Varsovia. Dpto. of Antarctic Biology, Polish Academy of Sciences.

- SERRANO, E. (2001): «Hielo, montañas, mar y fauna. El turismo en las islas Shetland del Sur (Antártida marítima)», Revue de Geographie Alpine, Monográfico Montagnes et Turisme (en prensa).

- SimmOnS, I.G. (1996): Changing the face of the Earth. Culture, Environment, History. Cambridge, Blackwell Publisher.

- VICTOR, P.E. (1965): El hombre a la conquista de los Polos. Barcelona. Ed. Destino. 
FIGURA 1. Localización de las islas Shetland del Sur en el continente antártico.

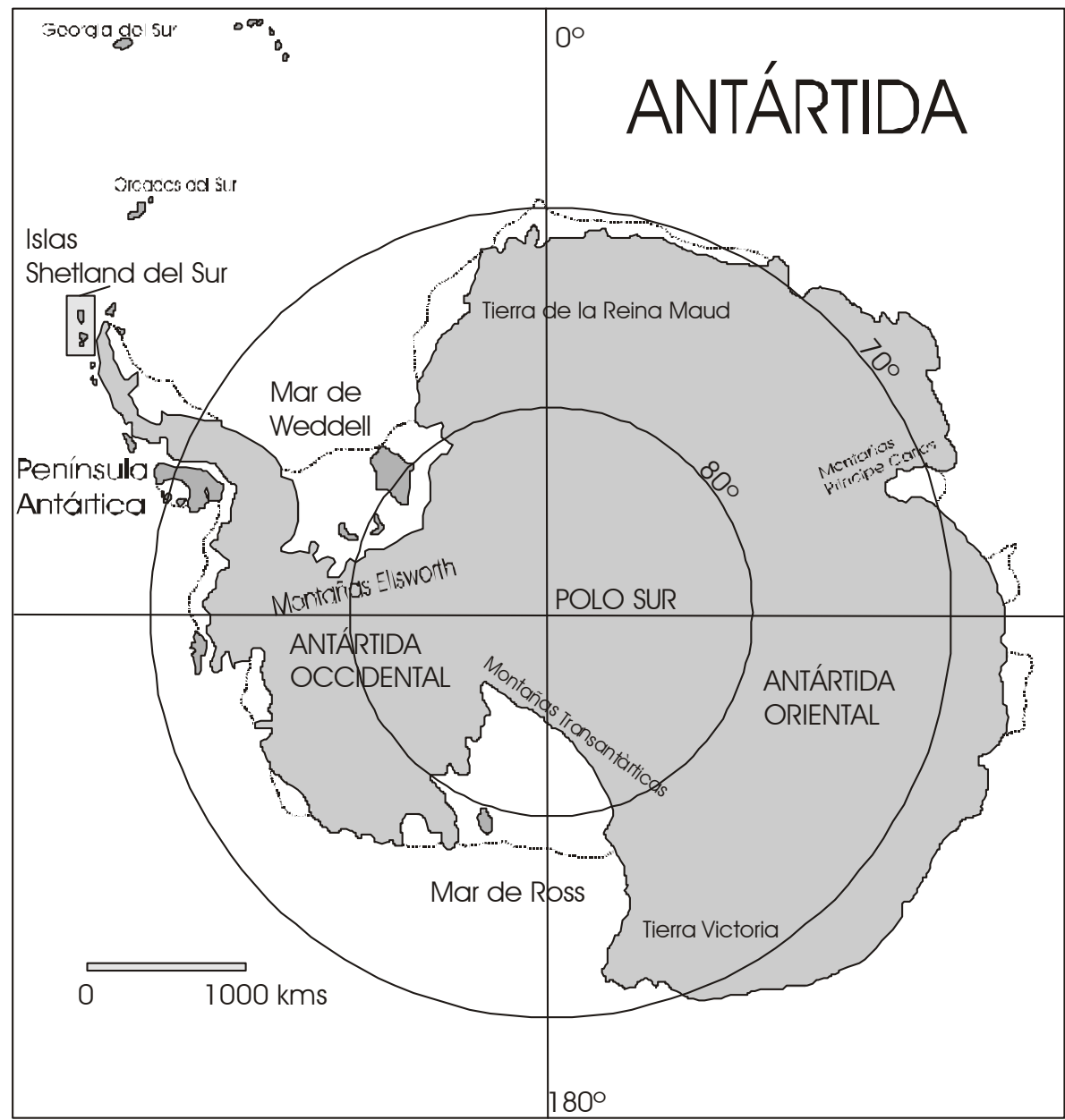


FIGURA 2. Localización de las bases científicas en las islas Shetland del Sur.

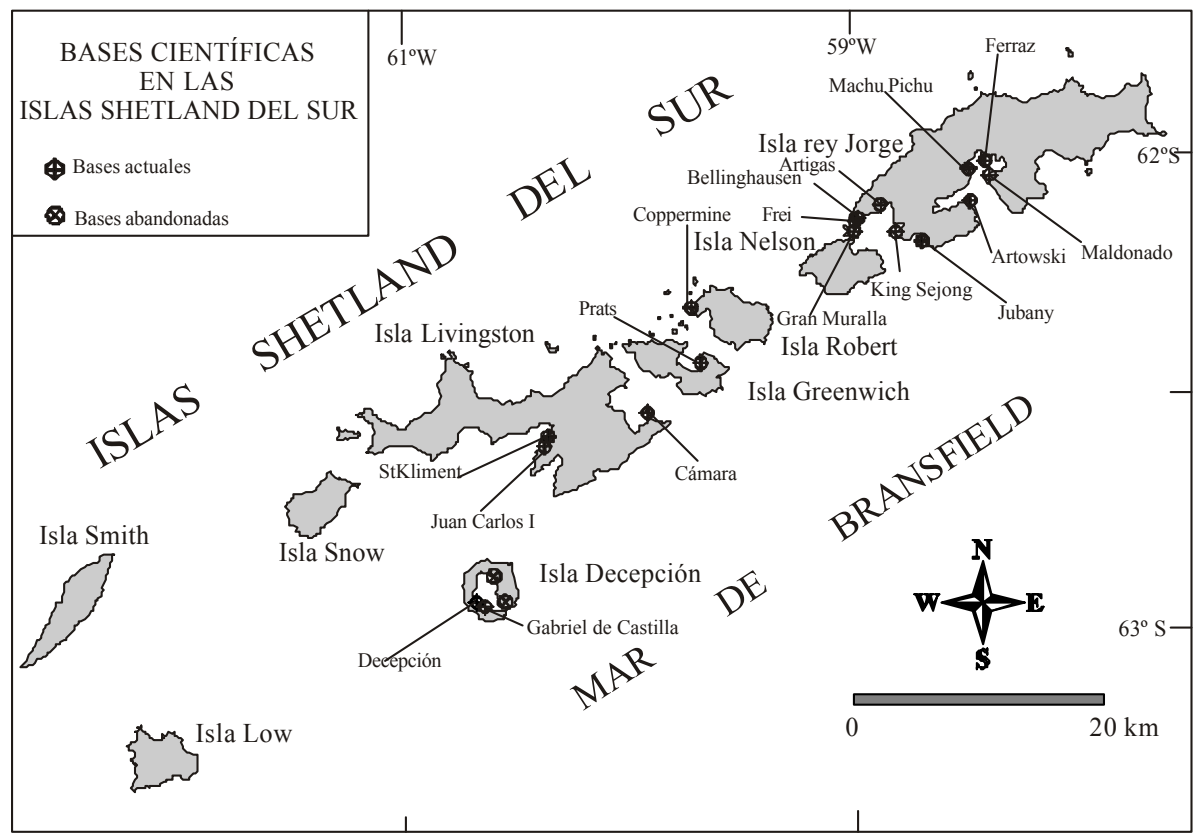

FIGURA 3. Plano de la base Gran Muralla (China) en la isla Rey Jorge, península Fildes.(FUENTE: Mapa Topográfico Ejército chileno, 1998).

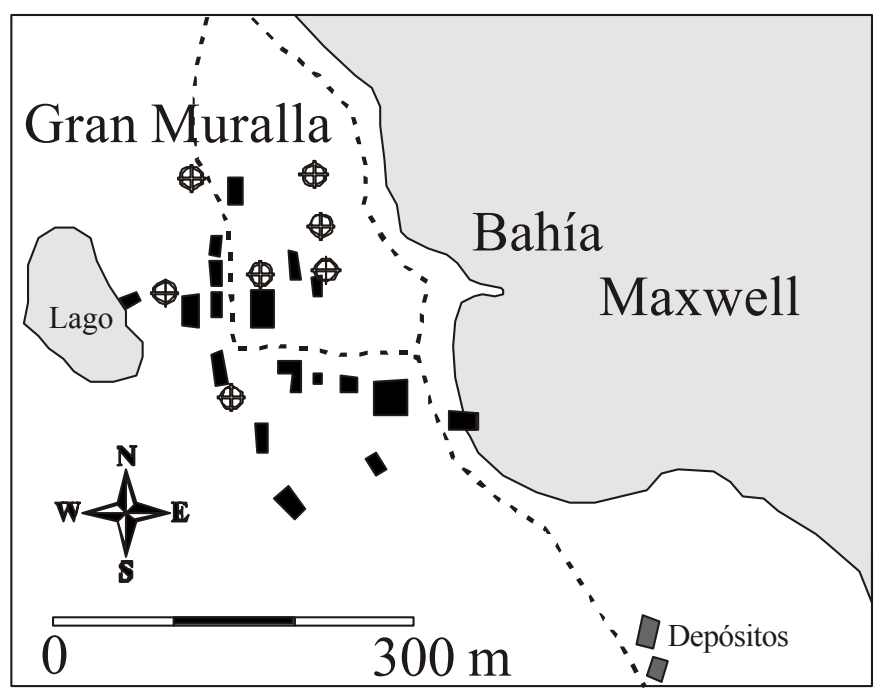


FIGURA 4. Plano de la base científica Artigas, Instituto Antártico Uruguayo, en la Península Fildes, isla rey Jorge. (FUENTE: Mapa Topográfico Ejército chileno, 1998).

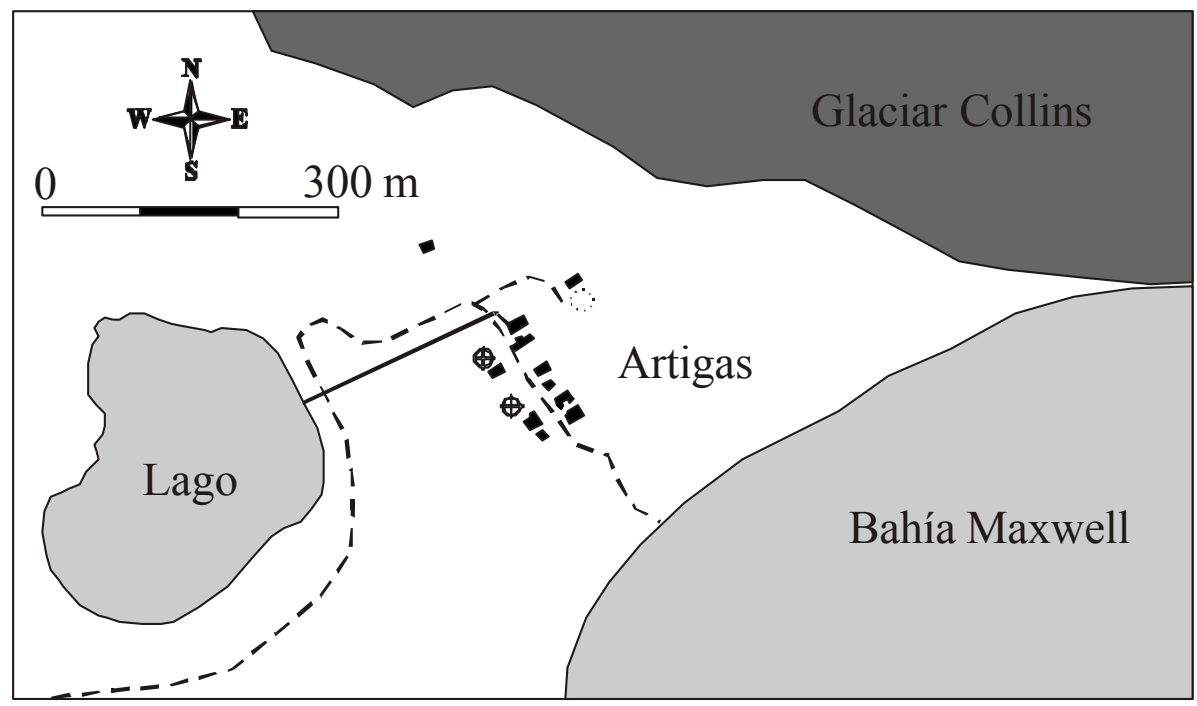


FIGURA 5. Aglomeración de las bases Frei (Chile), Bellinghausen (Rusia) y aeródromo Marsh (Chile), en la península Fildes, isla Rey Jorge. (FUENTE: Mapa Topográfico Ejército chileno, 1998).

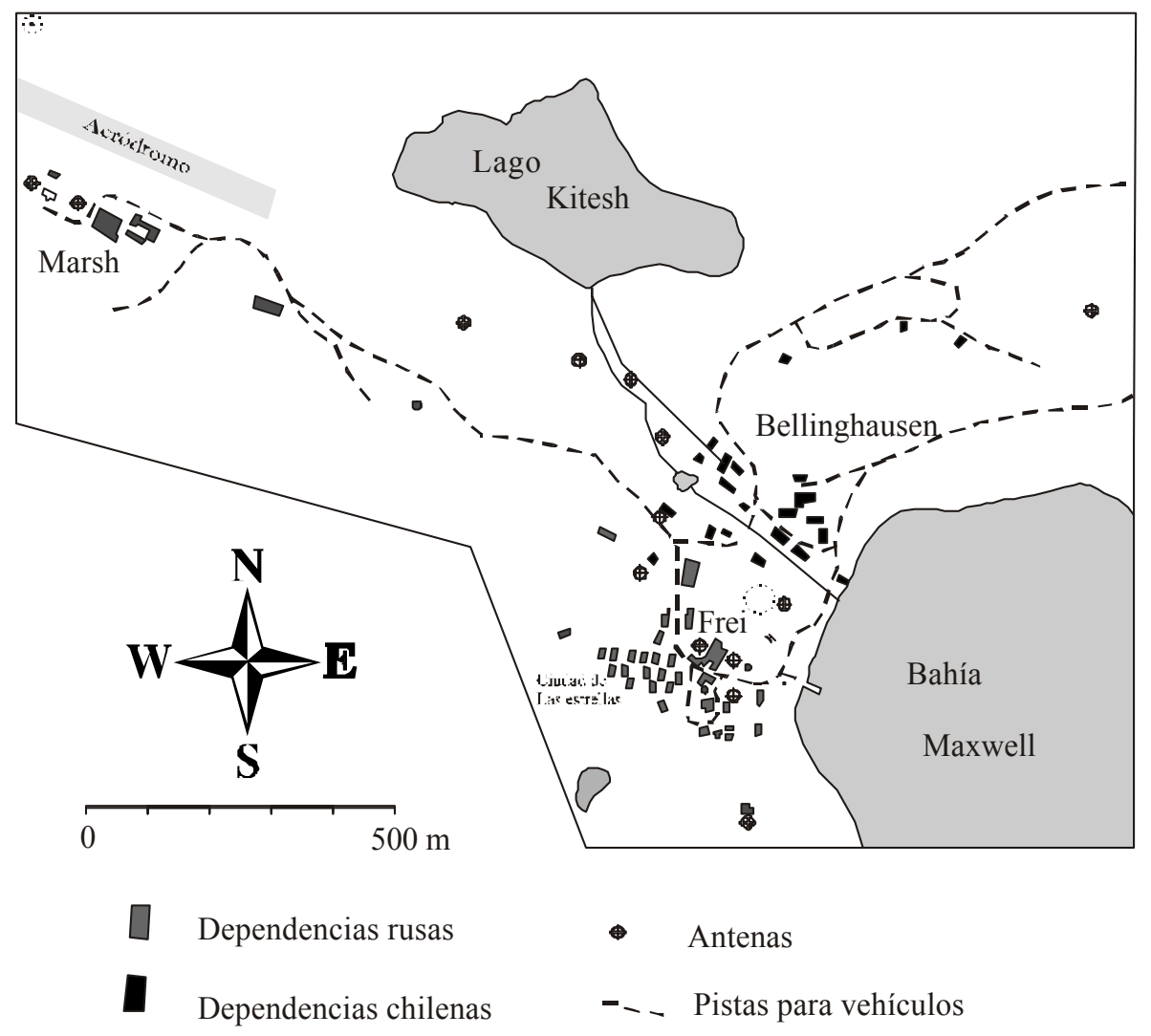




\section{FIGURA 6. Esquema de la distribución interna de la base Antártica Españo- la Juan Carlos I, en la isla Livingston.}

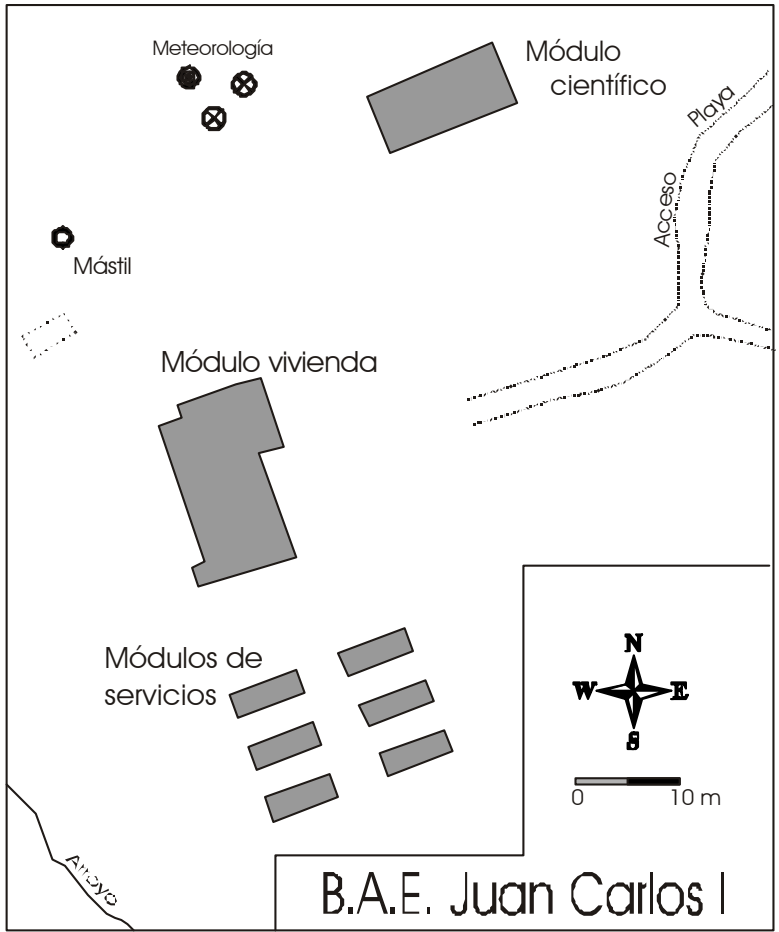

RESUMEN: En las Islas Shetland del Sur se ubican diecisiete bases científicas pertenecientes a doce naciones. Con una capacidad próxima al millar de personas, que implica una fuerte presión estival sobre el medio por el incremento de científicos, visitantes y turistas, en invierno queda reducida a menos de doscientas. La red de asentamientos responde a intereses políticos y geoestratégicos hasta los años setenta y posteriormente a los interéses logísticos y científicos, con una una tendencia a concentrarse en la isla Rey Jorge. Las bases son asentamientos muy heterogéneos tanto por su tipología como finalidad y evolución y responden a la historia y visicitudes de los programas antárticos nacionales. Las alteraciones e impactos de las bases de las Shetland del Sur poseen una entidad regional sin repercusiones continentales ni globales, centrados en las zonas libres de hielo de su entorno.

$P A L A B R A S C L A V E$ : bases científicas, población, impacto humano, alteraciones ambientales, islas Shetland del Sur, Antártida.

ABSTRACT. Science and settlement in South Shetland Island (maritime antarctic). Territorial and environmental involvements of scientific stations. In the South Shetland Island there are17 scientific stations of 12 differents nations. They have one thousand persons of capacity, reduced in 
winter to aproximatly two hundred persons. The scientific population, visitors and tourist, have a important influence on environment. The scientific stations net have been formed by politic and geostrategic interest, until seventy years, and logistic and scientific interest in eighty and ninety years. The scientific station are very heterogeneous by tipology, evolution and objetive, and they are the answer to the history and evolution of the national antarctic programs. The impacts and at terations of scientific stations have a regional scale and they are concentrated in the setting of ice free zones.

KEY WORDS. Scientific stations, population, human impact, environmental alteration, South Shetland Island, Antarctica.

$\boldsymbol{R E} \boldsymbol{S} \boldsymbol{U} \boldsymbol{M E}$ : Dans les îles Shetland du Sud on trouve dix-sept bases scientifiques qui appartiennent à douze nations. Avec une capacité d'environ un millier de personnes, ce qui implique une forte pression estivale sur l'environnement due à l'augmentation des scientifiques, visiteurs et touristes, cette capacité se réduit à moins de deux cents personnes en hiver. Le réseau des installations répond à des intérêts politiques, géographiques et stratégiques jusque dans les années soixantedix puis à des intérêts logistiques et scientifiques, avec une tendance à se concentrer dans l'île du Roi Georges. Les bases sont des installations très hétérogènes aussi bien en ce qui concerne leur typologie que leur but et leur évolution, et elles répondent à l'histoire et aux vicissitudes des programmes antarctiques nationaux. Les altérations et les impacts des bases des îles Shetland du Sud ont une importance régionale sans aucune répercussions continentales ni globales, et sont délimités aux zones libres de glace de leur environnement.

MOTS-CLÉS: bases scientifiques, population, impact humain, altérations de l'environnement, îles Shetland du Sud, Antarctide. 